Document downloaded from:

http://hdl.handle.net/10251/93329

This paper must be cited as:

Herrera Gamboa, MP.; Gómez-Martín, ME.; Medina, JR. (2017). Hydraulic stability of rock armors in breaking wave conditions. Coastal Engineering. 127:55-67.

doi:10.1016/j.coastaleng.2017.06.010

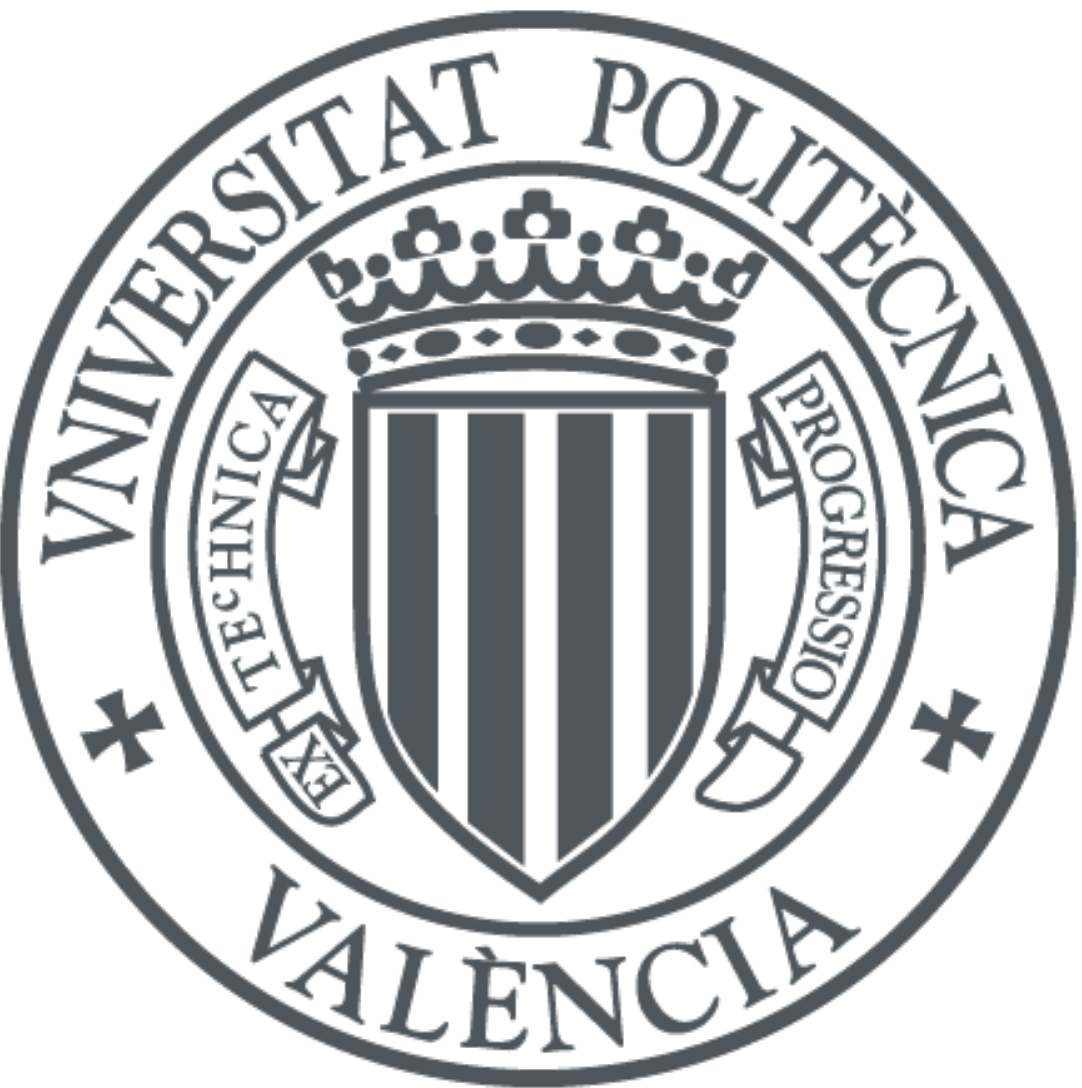

The final publication is available at

http://dx.doi.org/10.1016/j.coastaleng.2017.06.010

Copyright Elsevier

Additional Information 


\title{
Hydraulic stability of rock armors in breaking wave conditions
}

\author{
Maria P. Herrera ${ }^{a, *}$, M. Esther Gómez-Martín ${ }^{b}$ and Josep R. Medina ${ }^{c}$ \\ a Research Assistant, Dept. of Transportation, Universitat Politècnica de València, Camino de Vera s/n, 46022 \\ Valencia, Spain. E-mail: mahergam@upv.es (*corresponding author) \\ ${ }^{b}$ Assistant Professor, Dept. of Transportation, Universitat Politècnica de València, Camino de Vera s/n, 46022 \\ Valencia, Spain. E-mail: $\underline{\text { mgomar00@upv.es }}$ \\ c Professor, Dept. of Transportation, Universitat Politècnica de València, Camino de Vera s/n, 46022 Valencia, Spain. \\ E-mail: jrmedina@upv.es
}

\section{ABSTRACT}

Armor layers of mound breakwaters are usually designed with empirical formulas based on small-scale tests in non-breaking wave conditions. However, most rubble mound breakwaters are constructed in the depth-induced breaking zone, where they must withstand design storms having some percentage of large waves breaking before reaching the structure; in these cases, the design formulas for non-breaking wave conditions are not fully valid. To characterize double-layer rock armor damage in breaking wave conditions, 2D physical model tests were carried out with a bottom slope $m=1 / 50$. In order to develop a simple method to determine the wave parameters in the depth-induced breaking zone, experimental wave measurements were compared to the numerical estimations given by the SwanOne model. An analysis was conducted to select the best characteristic wave height to estimate rock armor damage when dealing with depth-induced breaking waves; the spectral significant wave height, $H_{m o}$, estimated at a distance of $3 h_{s}$ seaward from the structure toe, was found to be the most adequate. 
A new hydraulic stability formula is proposed for double-layer rock armors in breaking wave conditions, considering the observed potential 6-power relationship between the equivalent dimensionless armor damage and the $H_{m o}$ at $3 h_{s}$ seaward distance from the structure toe.

Keywords: Rock armor; Hydraulic stability; Rubble mound breakwaters; Breaking wave conditions; Shallow water.

Highlights:

a) Design formulas for rock armors are based mostly on physical tests in nonbreaking wave conditions.

b) In breaking wave conditions, most armor hydraulic stability formulas are not fully valid.

c) In breaking wave conditions, armor damage shows a 6-power relationship with $H_{m 0}$ at $3 h_{s}$ seaward distance from the structure toe.

d) The SwanOne numerical model is a suitable tool to estimate wave characteristics in breaking wave conditions.

\section{Introduction}

Iribarren [1, 2], Hudson [3], USACE [4, 5], Van der Meer [6], Melby and Kobayashi [7], Van Gent et al. [8] and others have reported different hydraulic stability formulas to design rock armors. Most of these formulas are based on tests carried out in nonbreaking wave conditions. Some empirical modifications have been proposed to estimate rock armor damage in breaking wave conditions in which the largest waves 
break before reaching the structure due to the depth effect; nevertheless, very few physical model tests have been conducted to validate formulas in breaking wave conditions.

Armor design in breaking wave conditions usually involves estimating an incident characteristic wave height at the toe of the structure, typically the significant wave height $H_{s}=H_{1 / 3}$ (average of one-third highest waves) or a wave height with a prescribed low exceedance probability $\left(H_{1 \%}, H_{2 \%}\right.$, etc.). When wave heights approximately follow the Rayleigh distribution (deep water), $H_{1 \%}$ and $H_{2} \%$ are highly correlated to $H_{s}$; however, this does not occur when the wave height distribution is affected by wave breaking. Numerous attempts have been made to find a distribution for wave heights in the depthinduced wave breaking zone. Glukhovsky [9] proposed using a Weibull distribution; Hughes and Borgman [10] proposed a Beta-Rayleigh distribution; Battjes and Groenendijk [11] used a composite Weibull distribution (CWD); Méndez et al. [12] proposed a modified Rayleigh distribution, while Méndez and Castanedo [13] and others recommended a distribution for the maximum wave height. Nonetheless, the hydraulic stability formulas found in the literature rarely take into consideration the relevant change of wave height distribution in the depth-induced wave breaking zone.

This study focuses attention on the hydraulic stability of double-layer rock armors in breaking wave conditions. To this end, new physical model tests were carried out at the wave flume of the Laboratory of Ports and Coasts at the Universitat Politècnica de València (LPC-UPV) with a $m=1 / 50$ bottom slope. Experimental wave measurements were compared to the estimations provided by the SwanOne numerical model (see Verhagen et al. [14]) in order to establish a rational procedure to determine the wave 
characteristics in the depth-induced breaking zone. Using both experimental results and SwanOne estimations, an analysis was conducted to identify which characteristic wave height and distance from the toe structure best determine armor damage evolution in breaking wave conditions. In this paper, existing formulas to design rock armor layers in breaking wave conditions are first compared. Secondly, the experimental setup and SwanOne simulations are described. Thirdly, results are analyzed. Fourthly, a new hydraulic stability formula for rock armors in breaking wave conditions is given and a comparison with existing formulas is provided. Finally, conclusions are drawn.

\section{Hydraulic stability of rock armors in breaking wave conditions}

This section describes the most commonly used hydraulic stability formulas to design rock armors in breaking wave conditions. The stability number, $N_{s}=H /\left(\Delta D_{n 50}\right)$, is normally used to characterize hydraulic stability, where $D_{n 50}=\left(M_{50} / \rho_{r}\right)^{1 / 3}$ is the nominal diameter of the rocks in the armor, $M_{50}$ is the median rock mass, $\rho_{r}$ is the mass density of the rocks, $\Delta=\left(\rho_{r}-\rho_{w}\right) / \rho_{w}$ is the relative submerged mass density, $\rho_{w}$ is the mass density of the sea water, and $H$ is a characteristic wave height.

Eq. (1) is equivalent to Hudson's [3] formula, which was popularized by USACE [4, 5] and based on the pioneering work of Iribarren [1]. Eq. (1) was validated with regular wave tests in non-breaking wave conditions. USACE $[4,5]$ recommended a change in the stability coefficient $\left(K_{D}\right)$ to use Eq. $(1)$ in breaking wave conditions. $K_{D}$ takes into account the geometry of the armor unit, number of layers, breakwater section (trunk or head) and an implicit safety factor for design; cot $\alpha$ is the armor slope.

$$
\frac{H}{\Delta D_{n 50}}=\left(K_{D} \cot \alpha\right)^{1 / 3}
$$


USACE [4] and USACE [5] proposed using $H=H_{s}=H_{1 / 3}$ and $H=H_{1 / 10}$ at the toe of the structure, respectively. According to USACE [4], using $H=H_{s}$, the stability coefficient for two-layer randomly-placed rough-angular rock armor was $K_{D}=3.5$ for breaking waves and $K_{D}=4.0$ for non-breaking waves. According to USACE [5], using $H=H_{1 / 10}$, the stability coefficient for two-layer randomly-placed rough-angular rock armor was $K_{D}=2.0$ for breaking waves $\left(H_{1 / 10}<1.27 H_{s}\right)$ and $K_{D}=4.0$ for non-breaking waves $\left(H_{1 / 10} \approx 1.27 H_{s}\right)$. Compared to USACE [4], USACE [5] significantly increased the implicit safety factor of rock armors.

Feuillet et al. [15] suggested a method to use Eq. (1) in breaking wave conditions taking into account the influence of shoaling and wave capping. This method provided the design wave height, $H$, to be used in Eq. (1) for $m=1 / 100,1 / 20$ and $1 / 10$ bottom slopes, as a function of the wave steepness, the water depth at the toe, and the offshore $H_{1 / 10}$. Jensen et al. [16] recommended $H_{1 / 20}$ to characterize the irregular waves attacking the structure.

Eq. (1) refers to no-damage $(0-5 \%$ of the volume of armor units displaced from the armor active zone). To estimate higher damage levels, the armor damage results corresponding to rough quarrystones provided by USACE [4] can be used. Using the dimensionless armor damage parameter $S=A_{e} / D_{n 50}{ }^{2}$, suggested by Broderick [17] and popularized by Van der Meer [18], where $A_{e}$ is the average eroded area in the breakwater's section, Medina et al. [19] reported a 5-power relationship between $\mathrm{H}$ and armor damage for non-breaking wave conditions. Appendix A adapts the methodology given in Medina et al. [19] to be used in this study. 
Van der Meer [6] proposed Eqs. (2a) and (2b) to predict rock hydraulic stability under wave attack, based on irregular laboratory tests performed at Delft Hydraulics and the previous work conducted by Thompson and Shuttler [20]. Most of the tests were carried out in non-breaking wave conditions covering a wide range of armor slopes ( $\cot \alpha=1.5$, 2.0, 3.0, 4.0 and 6.0), stability numbers $\left(1 \leq H_{s} / \Delta D_{n 50} \leq 4\right)$ and core permeability. Eqs. (2a) and (2b) are applicable to "plunging" and "surging" waves, which refer to the type of wave breaking on the armor slope.

$$
\begin{aligned}
& \frac{H_{s}}{\Delta D_{n 50}}=6.2 S^{0.2} P^{0.18} N_{z}^{-0.1} \xi_{m}{ }^{-0.5} \quad \text { for } \quad \xi_{m}<\xi_{m c} \text { (plunging waves) } \\
& \frac{H_{s}}{\Delta D_{n 50}}=1.0 S^{0.2} P^{-0.13} N_{z}{ }^{-0.1}(\cot \alpha)^{0.5} \xi_{m}{ }^{P} \text { for } \quad \xi_{m}>\xi_{m c} \text { (surging waves) }
\end{aligned}
$$

in which $\left.\xi_{m c}=6.2 P^{0.31}(\tan \alpha)^{0.5}\right)^{1 /(P+0.5)}$ is the critical breaker parameter, $0.1 \leq P \leq 0.6$ is a parameter which considers the permeability of the structure, $N_{z}$ is the number of waves, and $\xi_{m}=\tan \alpha /\left(2 \pi H_{s} /\left(g T_{m}^{2}\right)\right)^{0.5}$ is the surf similarity parameter based on the mean period, $T_{m}$.

Additionally, Van der Meer [6] conducted 16 physical tests in breaking wave conditions with a $m=1 / 30$ bottom slope and a permeable structure with nominal diameter of rocks $D_{n 50}(\mathrm{~cm})=3.6$, armor slope $\cot \alpha=2.0,1.6 \leq H_{s} / \Delta D_{n 50} \leq 2.5$ and $3.3 \leq h_{s} / \Delta D_{n 50} \leq 6.5$. For breaking wave conditions, Van der Meer [6] replaced $H_{s}$ in Eqs. (2a) and (2b) by $H_{2 \%} / 1.4$; the factor 1.4 corresponds to the ratio $H_{2} \% / H_{s}$ in the Rayleigh distribution (deep water). Lamberti et al. [21] analyzed how the water depth reshaped rubble mound breakwaters in deep and shallow water conditions. They conducted physical model tests with an initial horizontal bottom slope for deep water conditions, then with a $m=1 / 20$ bottom slope for intermediate water depths, and a $m=1 / 100$ bottom slope to represent shallow 
water conditions. These authors concluded that $H_{1 / 50}$ at the toe of the structure was a good representative wave height to estimate armor damage.

Melby and Kobayashi [7] studied the progression and variability of armor damage on rubble mound breakwaters with a bottom slope $m=1 / 20$ and water depths at the toe $h_{s}(\mathrm{~cm})=11.9$ and 15.8. Damage to a double-layer rock armor with coto=2 and $D_{n 50}(\mathrm{~cm})=3.64$ was measured after three test series of long duration using a profiler. Melby [22] provided a method to compute damage using the empirical equation (Eq. 3) proposed by Melby and Kobayashi [7] to consider cumulative damage for the wave parameters varying in steps in the ranges $1.6 \leq H_{s} / \Delta D_{n 50} \leq 2.5$ and $2.0 \leq h_{s} / \Delta D_{n 50} \leq 2.6$.

$S(t)=S\left(t_{n}\right)+0.025\left(\frac{H_{s}}{\Delta D_{n 50}}\right)^{5} \frac{\left(t^{0.25}-t_{n}^{0.25}\right)}{\left(T_{m}\right)^{0.25}} \quad$ for $t_{n} \leq t \leq t_{n+1}$

where $S(t)$ and $S\left(t_{n}\right)$ are the mean armor damage at times $t$ and $t_{n}$, respectively, with $t>t_{n}$ $\left(t=T_{m} N_{z}\right), T_{m}$ is the mean period and $N_{z}$ is the number of waves. Incident and reflected waves were separated using three wave gauges placed close to the breakwater, and the methodology described by Kobayashi et al. $[23,24]$. Eq. (3) was calibrated with $H_{s}$ obtained at the wave gauge closest to the structure $(0.91 \mathrm{~m}$ from the toe), which corresponded approximately to distances between $5.7 h_{s}$ and $7.6 h_{s}$ from the toe.

Van Gent et al. [8] modified Eqs. (2a) and (2b) based on results from tests carried out by Smith et al. [25] and new 2D physical tests in breaking and non-breaking wave conditions. These new tests were conducted with two bottom slopes $(m=1 / 30$ and $1 / 100)$, two armor slopes $(\cot \alpha=2$ and 4$)$, three rock nominal diameters $\left(D_{n 50}(\mathrm{~cm})=2.2\right.$, 2.6 and 3.5) with an aspect ratio $L T=2.1$ (see CIRIA/CUR/CETMEF [26]) and different 
breakwater geometries. Eqs. (4a) and (4b) are the modified hydraulic stability formulas proposed by Van Gent et al. [8] calibrated with tests in breaking and non-breaking wave conditions in the ranges $0.5 \leq H_{s} / \Delta D_{n 50} \leq 4.5$ and $1.5<h_{s} / \Delta D_{n 50}<11$. Eqs. (4a) and (4b) are similar to Eqs. (2a) and (2b) but refer the surf similarity parameter to $T_{m-1,0}$ rather than the mean period, $T_{m}$.

$$
\begin{array}{ll}
\frac{H_{2 \%}}{\Delta D_{n 50}}=8.4 S^{0.2} P^{0.18} N_{z}^{-0.1} \xi_{s-1}{ }^{-0.5} & \text { for } \xi_{s-1}<\xi_{m c} \text { (plunging waves) (4a) } \\
\frac{H_{2 \%}}{\Delta D_{n 50}}=1.3 S^{0.2} P^{-0.13} N_{z}^{-0.1}(\cot \alpha)^{0.5} \xi_{s-1}^{P} & \text { for } \xi_{s-1}>\xi_{m c} \text { (surging waves) (4b) }
\end{array}
$$

in which $\xi_{s-1}=\tan \alpha /\left(2 \pi H_{s} /\left(g T_{m-1,0}{ }^{2}\right)\right)^{0.5}$ is the surf similarity parameter based on the spectral period $T_{m-1,0}=\frac{m_{-1}}{m_{0}}$, where $m_{i}$ is the $i$-th spectral moment, $m_{i}=\int_{0}^{\infty} S(f) f^{i} d f$, being $S(f)$ the wave spectrum. Incident wave parameters were obtained in the breaking zone from physical tests conducted without a structure. $\mathrm{H}_{2 \%}$ at the toe of the structure was selected as the characteristic wave height.

Additionally, Van Gent et al. [8] proposed Eq. (5) taking into account the influence of the

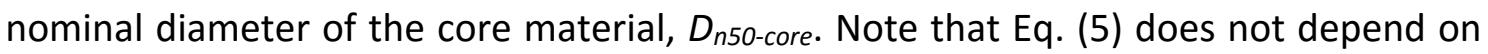
the wave period.

$$
\frac{H_{s}}{\Delta D_{n 50}}=1.75\left(1+\frac{D_{n 50-\text { core }}}{D_{n 50}}\right)\left(\frac{S}{N_{z}}\right)^{0.2}(\cot \alpha)^{0.5}
$$

In this case, $H_{s}$ at the toe of the structure was selected as the characteristic wave height. Hovestad [27] conducted specific physical tests in breaking wave conditions to determine the effect of the bottom slope on armor stability. A homogeneous rock armored breakwater with $\cot \alpha=2$ and $D_{n 50}(\mathrm{~cm})=1.57$ was tested with two different bottom slopes: a gentle bottom slope $m=1 / 30$ and a steep bottom slope $m=1 / 8$. After 
re-analyzing Hovestad's data, Muttray and Reedijk [28] concluded that the most significant increase in damage occurred with steep bottom slopes. Verhagen et al. [29] and Herrera and Medina [30] also pointed out a significant increase in non-linear effects and wave loads on the armor and the toe berm of mound breakwaters placed on steep sea bottoms. CIRIA/CUR/CETMEF [26] proposed reducing by $10 \%$ the stability number of single-layer armors when dealing with breaking waves and steep sea bottoms.

Using experimental data given by Thompson and Shuttler [20] in non-breaking wave conditions, Vidal et al. [31] demonstrated that the average wave height of the 50 highest waves attacking the breakwater, $H_{50}$, was the wave parameter that best represents the armor damage evolution over time.

Prevot et al. [32] conducted specific physical model tests in breaking wave conditions with a bottom slope $m=1 / 30$ to compare the damage measured in a double-layer rock armor and the estimations given by Eqs. (4a), (4b) and (5), and Eq. (1) when using the method described by Feuillet et al. [15]. According to Prevot et al. [32], the best fit was found for Eqs. (4a) and (4b).

Although several hydraulic stability formulas for rock armors are used in breaking wave conditions, most experimental validations are done in non-breaking wave conditions. Only Melby and Kobayashi [7] and Van Gent et al. [8] obtained hydraulic stability formulas based on specific laboratory tests in breaking wave conditions for a bottom slope $m=1 / 20$ with armor slope $\cot \alpha=2$, and bottom slopes $m=1 / 30$ and $1 / 100$ with $\cot \alpha=2$ and 4, respectively. Furthermore, available formulas require knowing $H_{s}$ or $H_{2 \%}$ at the toe of the structure; however, they were calibrated with waves measured at a certain distance from the structure. Melby and Kobayashi [7] and Van Gent et al. [8] did 
not recommend a specific method to estimate $H_{s}$ and $H_{2}$ in the depth-induced wave breaking zone.

This study provides a methodology to analyze the hydraulic stability of double-layer randomly-placed rock armors in breaking wave conditions with bottom slope $m=1 / 50$ and armor slope $\cot \alpha=1.5$. The spectral significant wave height, $H_{m 0}$, estimated at a distance of $3 h_{s}$ seaward from the structure toe by the numerical model SwanOne, is recommended to characterize the waves attacking the structure in breaking wave conditions.

\section{Methodology}

\subsection{Physical model tests}

2D physical model tests were conducted in the wind and wave test facility $(30 \times 1.2 \times 1.2$ $m$ ) of the LPC-UPV with a bottom slope $m=1 / 50$. Fig. 1 shows a longitudinal cross section of the LPC-UPV wave flume, and Fig. 2 shows the cross section of the physical model.

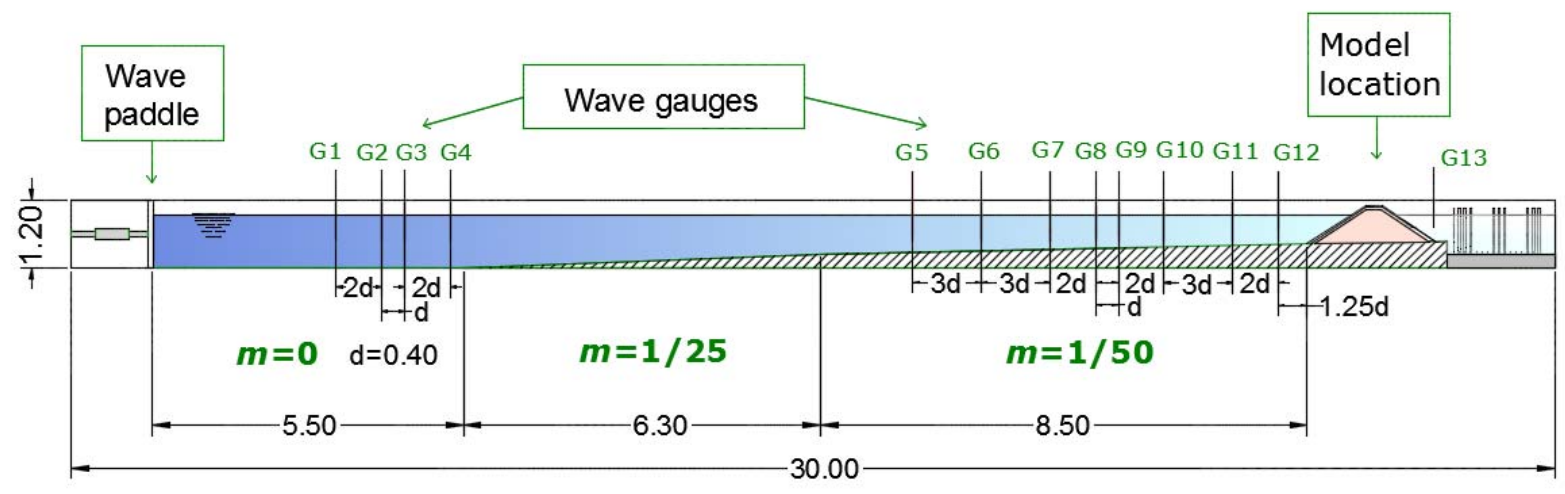

Fig. 1. Longitudinal cross section of the LPC-UPV wave flume (dimensions in meters). 
The model cross section depicted in Fig. 2 is a non-overtopping rubble mound breakwater without a toe berm; it is protected with a double-layer randomly-placed rock armor with armor slope $\cot \alpha=1.5$, nominal diameter $D_{n 50}(\mathrm{~cm})=3.18$ and mass density $\rho_{r}\left(\mathrm{~g} / \mathrm{cm}^{3}\right)=2.677$. The mean value of the measured packing density of the armor layer was $\phi=1.26$ (value recommended by USACE [5]), which corresponds to an armor porosity $p=37 \%$ (see Medina et al. [33]). The shape of the rough angular rocks in the armor was characterized using the aspect ratio $(L T)$, and the Blockiness $(B L C)$ described by CIRIA/ CUR/ CETMEF [26]; the mean values of these two parameters were $L T=1.8$ and $B L C=42 \%$. The rock armor was placed on a filter layer with $D_{n 50}(\mathrm{~cm})=1.78$ and $D_{n 85} / D_{n 15}=1.35$. The characteristics of the core material were $D_{n 50}(\mathrm{~cm})=0.68$ and $D_{n 85} / D_{n 15}=1.64$. Considering a reference scale $1 / 40$, this structure corresponds to a double-layer 5.5-tonne rock armor. Table 1 summarizes the characteristics of the materials used in the physical model.

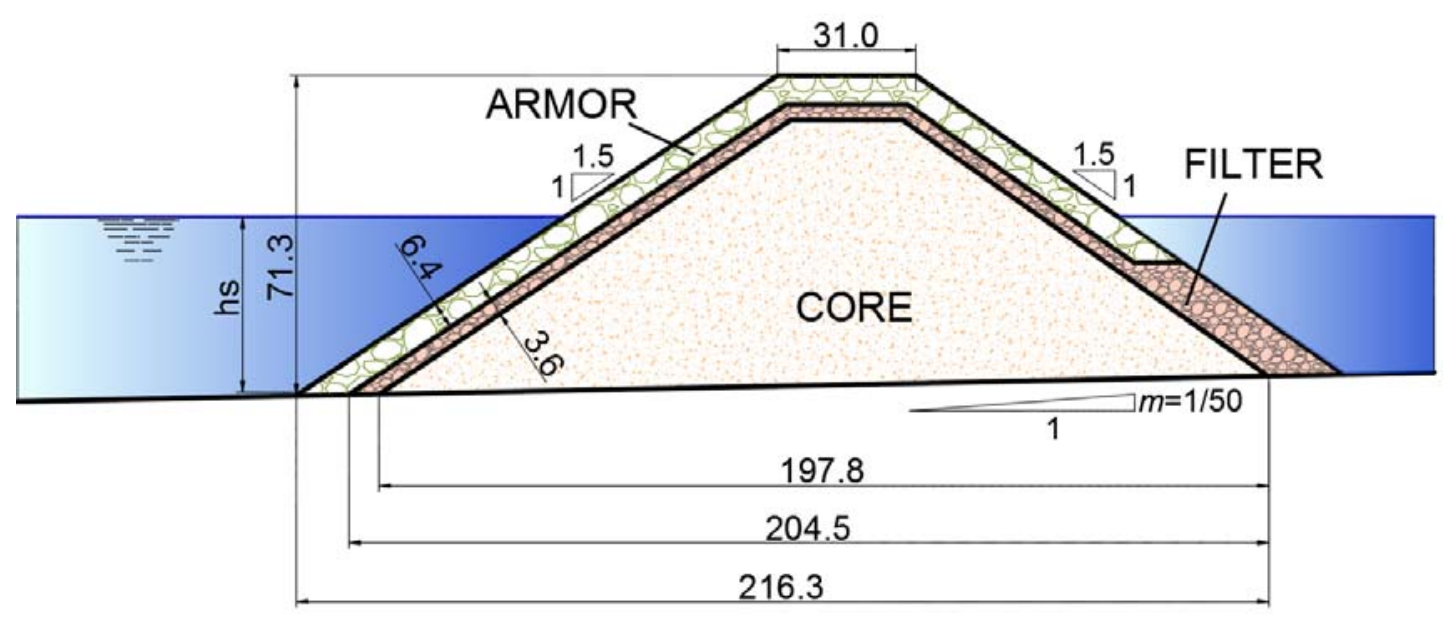

Fig. 2. Cross section of the rubble mound breakwater model (dimensions in centimeters). 
Table 1. Characteristics of the materials used in the physical model.

\begin{tabular}{lllll}
\hline Gravel & $M_{50}(\mathrm{~g})$ & $D_{n 50}(\mathrm{~cm})$ & $\rho_{r}\left(\mathrm{~g} / \mathrm{cm}^{3}\right)$ & $D_{n 85} / D_{n 15}$ \\
\hline Armor & 86.18 & 3.18 & 2.677 & 1.14 \\
Filter & 15.40 & 1.78 & 2.729 & 1.35 \\
Core & 0.86 & 0.68 & 2.722 & 1.64 \\
\hline
\end{tabular}

Three water depths at the toe of the structure were tested $\left(h_{s}(\mathrm{~cm})=20,30\right.$ and 40$)$. For each water depth, tests were grouped in two series of constant surf similarity parameter with the target values of $\xi_{p}=\tan \alpha /\left(2 \pi H_{m 0} /\left(g T_{p}{ }^{2}\right)\right)^{0.5}=3.0$ and 5.0, corresponding to wave steepnesses of $s_{0 p}=2 \pi H_{m o} /\left(g T_{p}^{2}\right)=0.049$ and 0.018 . For $h_{s}(\mathrm{~cm})=40$, tests conducted with $\xi_{p}=5.0$ were eliminated because relevant overtopping was observed during the experiments. For each series, spectral significant wave height, $H_{m 0}=4\left(m_{0}\right)^{1 / 2}$, was increased progressively in steps of $1 \mathrm{~cm}$ from zero-damage to initiation of destruction or wave breaking at the wave generating zone. For each test, random wave runs of 1000 waves were generated following JONSWAP $(\gamma=3.3)$ spectra. The AWACS Active Absorption System was activated to avoid multi-reflections in the wave flume. Table 2 summarizes the test characteristics considering waves in the wave generating zone.

Table 2. Test matrix.

\begin{tabular}{llllllll}
\hline Series & $h_{s}(\mathrm{~cm})$ & $\xi_{p}$ & sop & $H_{m o}(\mathrm{~cm})$ & $T_{p}(\mathrm{~s})$ & $\begin{array}{l}\text { Number of } \\
\text { test runs }\end{array}$ & $\begin{array}{l}\text { Number of } \\
\text { waves, } N_{z}\end{array}$ \\
\hline 1 & 20 & 3.0 & 0.049 & $8.0-18.0$ & $1.02-1.53$ & 11 & 1000 \\
2 & 20 & 5.0 & 0.018 & $8.0-15.0$ & $1.70-2.32$ & 8 & 1000 \\
3 & 30 & 3.0 & 0.049 & $8.0-17.0$ & $1.02-1.48$ & 10 & 1000 \\
4 & 30 & 5.0 & 0.018 & $8.0-14.0$ & $1.70-2.25$ & 7 & 1000 \\
5 & 40 & 3.0 & 0.049 & $8.0-16.0$ & $1.02-1.44$ & 9 & 1000 \\
\hline
\end{tabular}


Water surface elevation was measured using thirteen capacitive wave gauges. One group of wave gauges (G1, G2, G3 and G4) was placed near the wavemaker, another group of wave gauges along the wave flume and near the model $(G 5, G 6, G 7, G 8, G 9$, G10, G11 and G12), and one wave gauge (G13) was placed behind the model to monitor the water level at the rear of the structure (see Fig. 1). The separation between wave gauges was a multiple of $d(\mathrm{~cm})=40$.

Armor damage was measured after each test run considering the cumulative number of rocks displaced during the test series having constant $h_{s}$ and $\xi_{p}$. Comparing the photographs taken perpendicularly to the armor slope before and after each test run, the damage was characterized using the virtual net method developed by Gómez-Martín and Medina [34, 35] and the visual counting method described by Vidal et al. [31]. The virtual net method considers the armor divided into individual strips of a constant width, $a=q D_{n 50}$, and length, $b=k D_{n 50}$; it allows the dimensionless damage to be measured in each strip, $S_{i}$, considering porosity evolution in time and space. Integrating this dimensionless armor damage over the slope, the equivalent dimensionless armor damage parameter, $S_{e}$, was obtained using Eq. (6).

$$
S_{e}=\sum_{i=1}^{l} S_{i}=\sum_{i=1}^{l} q\left(1-\frac{1-p_{i}}{1-p_{i 0}}\right)=\sum_{i=1}^{l} q\left(1-\frac{\phi_{i}}{\phi_{i 0}}\right)
$$

in which $q$ is the number of rows in each strip, $p_{i}=1-\left(N_{i} D_{n}{ }^{2} / a b\right)$ and $\phi_{\mathrm{i}}=n\left(1-p_{i}\right)$ are the armor porosity and packing density of the strip $i, N_{i}$ is the number of armor units whose center of gravity is within each strip, $p_{0 i}$ and $\phi_{i 0}$ are the initial armor porosity and packing density of the strip $i, l$ is the number of strips, and $n$ is the number of rock armor layers. 
The visual dimensionless armor damage parameter, $S_{v}$, was estimated using the visual counting method described by Vidal et al. [31].

$S_{v}=\frac{A_{e v}}{D_{n 50}^{2}}=\frac{N_{e} D_{n 50}}{(1-p) b}$

where $A_{e v}$ is the average eroded area in the breakwater section, $N_{e}$ is the number of extracted units relocated above the upper layer, $p$ is the initial porosity of the armor layer and, $b$ is the observed width of the tested section.

Note that the visual counting method assumes a constant armor porosity, so changes in the porosity due to Heterogeneous Packing (HeP) are not considered. In contrast, the virtual net method simultaneously takes into account armor unit extractions, sliding of the armor layer as a whole, and HeP (see Gómez-Martín and Medina [35]).

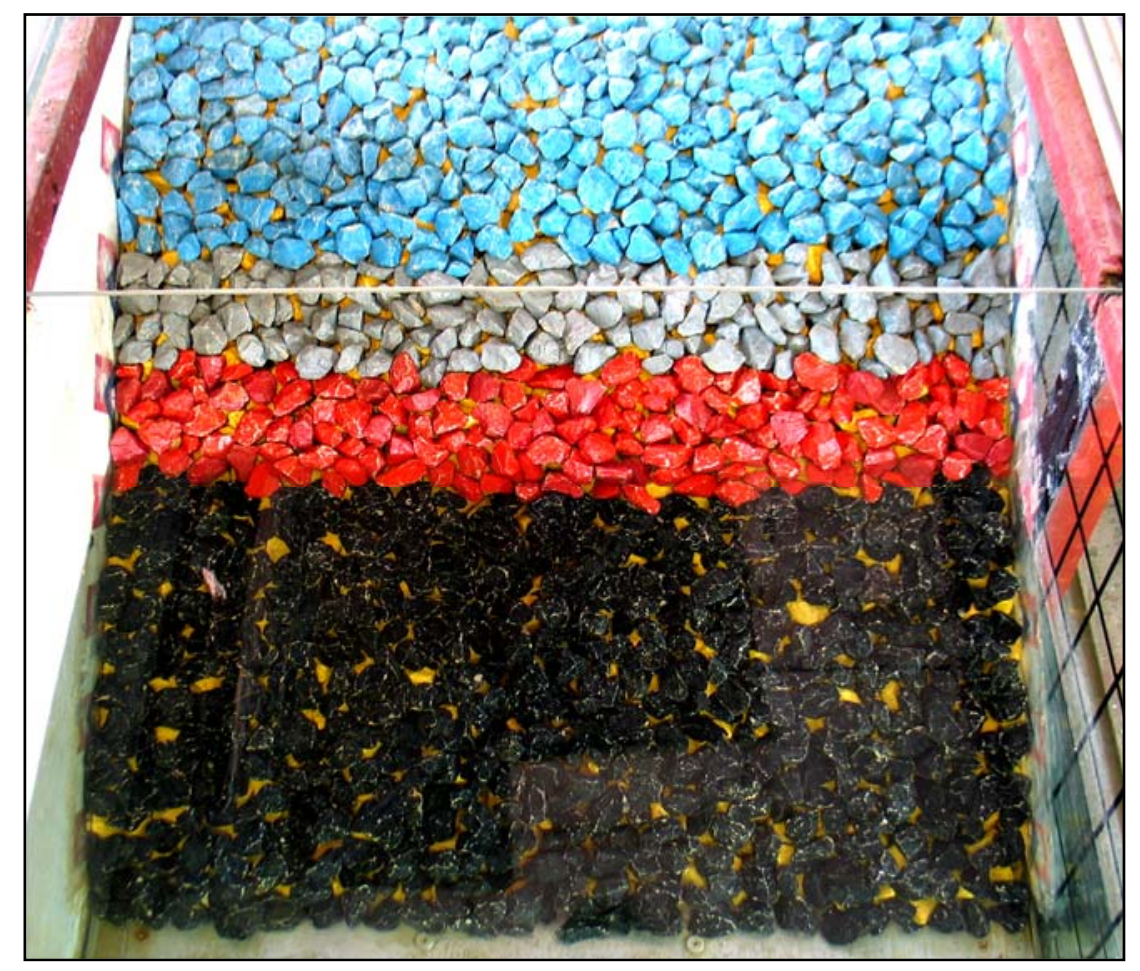

Fig. 3. Frontal view of the breakwater model. 
When completed, the tests were repeated without a structure to more accurately measure the incident wave heights close to the model. To reduce undesired reflection, an energy absorber was placed at the end of the wave flume.

\subsection{Numerical simulations}

Numerical simulations were carried out using the SwanOne software. SwanOne estimated wave propagation, simulating the depth-induced breaking phenomena. The test program (see Table 2) was repeated with the same bottom profile and wave characteristics as in the physical experiments. To analyze wave parameters, virtual wave measurements were taken from the locations of the thirteen wave gauges (G1 to G13) used in the physical tests. SwanOne provided the values of $H_{m 0}, T_{p}, T_{m}, T_{m-1,0}$ at these locations. The method proposed by Battjes and Groenendijk [11] was implemented to estimate $H_{1 / 10}$ and $H_{2}$ in the depth-induced wave breaking zone.

\section{Data analysis}

\subsection{Wave analysis}

Wave height distributions and spectral moments were estimated from the measured surface elevations with and without the breakwater model. For tests conducted with the structure, incident and reflected waves were separated in the wave generating zone (G1 to G4) using the LASA-V method developed by Figueres and Medina [36]. Existing methods to separate incident and reflected waves are not reliable when applied near the structure, in the depth-induced wave breaking zone. Incident waves were estimated close to the model from the total wave gauge records (average of $H_{m 0}$ or $H_{2 \%}$ measured 
at G11 and G12), considering the reflection coefficient $\left(K_{r}=H_{m 0, r} / H_{m 0, i}<0.40\right)$ measured at the wave generating zone (G1 to G4), where $H_{m 0, r}$ and $H_{m 0, i}$ are the reflected and incident spectral significant wave height, respectively. For tests conducted without the structure, the measured waves directly corresponded to the incident waves because an efficient wave absorption assembly was placed at the end of the wave flume. This assembly, formed by five groups of three metal frames with openings of decreasing porosity, reflected less than $4 \%$ of the energy of the incident waves $\left(K_{r}=H_{m 0, r} / H_{m 0, i}<0.20\right.$ measured at the wave generating zone).

Fig. 4a shows the incident $H_{m o}$ and $H_{2} \%$ estimated close to the model in the physical tests conducted with the structure (assuming constant $K_{r}=H_{m 0, r} / H_{m 0, i}$ ), compared to the incident $H_{m o}$ and $H_{2 \%}$ measured in the physical tests without the structure at G11 and G12 (average value). In order to measure the goodness of fit, the relative mean squared error, $r M S E$, and the correlation coefficient, $r$, were calculated:

$$
\begin{gathered}
r M S E=\frac{M S E}{\operatorname{Var}}=\frac{\frac{1}{N_{t}} \sum_{i=1}^{N_{t}}\left(t_{i}-e_{i}\right)^{2}}{\frac{1}{N_{t}} \sum_{i=1}^{N_{t}}\left(t_{i}-\bar{t}\right)^{2}} \\
r=\frac{\sum_{i=1}^{N_{t}}\left(t_{i}-\bar{t}\right)\left(e_{i}-\bar{e}\right)}{\sqrt{\sum_{i=1}^{N_{t}}\left(t_{i}-\bar{t}\right)^{2} \sum_{i=1}^{N_{t}}\left(e_{i}-\bar{e}\right)^{2}}}
\end{gathered}
$$

in which MSE is the mean squared error, $N_{t}$ is the number of observations, $t_{i}$ is the target value, $e_{i}$ is the estimated value, Var is the variance of target values, and $\bar{t}$ and $\bar{e}$ are the average of target and estimated values, respectively. $0 \leq r M S E \leq 1$ estimates the proportion of variance not explained by the model; the lower the $r M S E$, the better the 
predictions. $0 \leq r \leq 1$ measures the degree of correlation; the higher the $r$, the better the predictions. When considering $H_{m 0}, r M S E=0.069$ and $r=0.989$; when using $H_{2} \%$, $r M S E=0.067$ and $r=0.986$. As shown in Fig. $4 a$, there was a high correlation between the mean values of the incident wave heights obtained with and without the structure in gauges G11 and G12. Thus, the incident $H_{m 0}$ and $H_{2}$ obtained from the $K_{r}$ measured at the wave generating zone are good estimators of the actual incident $H_{m 0}$ and $H_{2 \%}$ attacking the breakwater when the reflection is not large $\left(K_{r} \leq 0.4\right)$. However, as measurements without a structure are more reliable to estimate actual incident waves, only the values obtained in tests without the breakwater model were considered hereafter when referring to incident wave measurements.

Experimental results were contrasted to numerical simulations. Fig. $4 \mathrm{~b}$ shows the mean value of $H_{m o}$ and $H_{2}$ estimated by SwanOne at the position of the wave gauges $\mathrm{G} 11$ and G12, compared to the mean value measured in the laboratory tests without the breakwater model. When $H=H_{m 0}, r M S E=0.058$ and $r=0.995$; when $H=H_{2 \%}, r M S E=0.105$ and $r=0.952$. There was also a high correlation between the measurements in laboratory and the predictions given by SwanOne for both $H=H_{m o}$ and $H=H_{2} \%$. However, the errors were lower when considering $H=H_{m 0}$. 

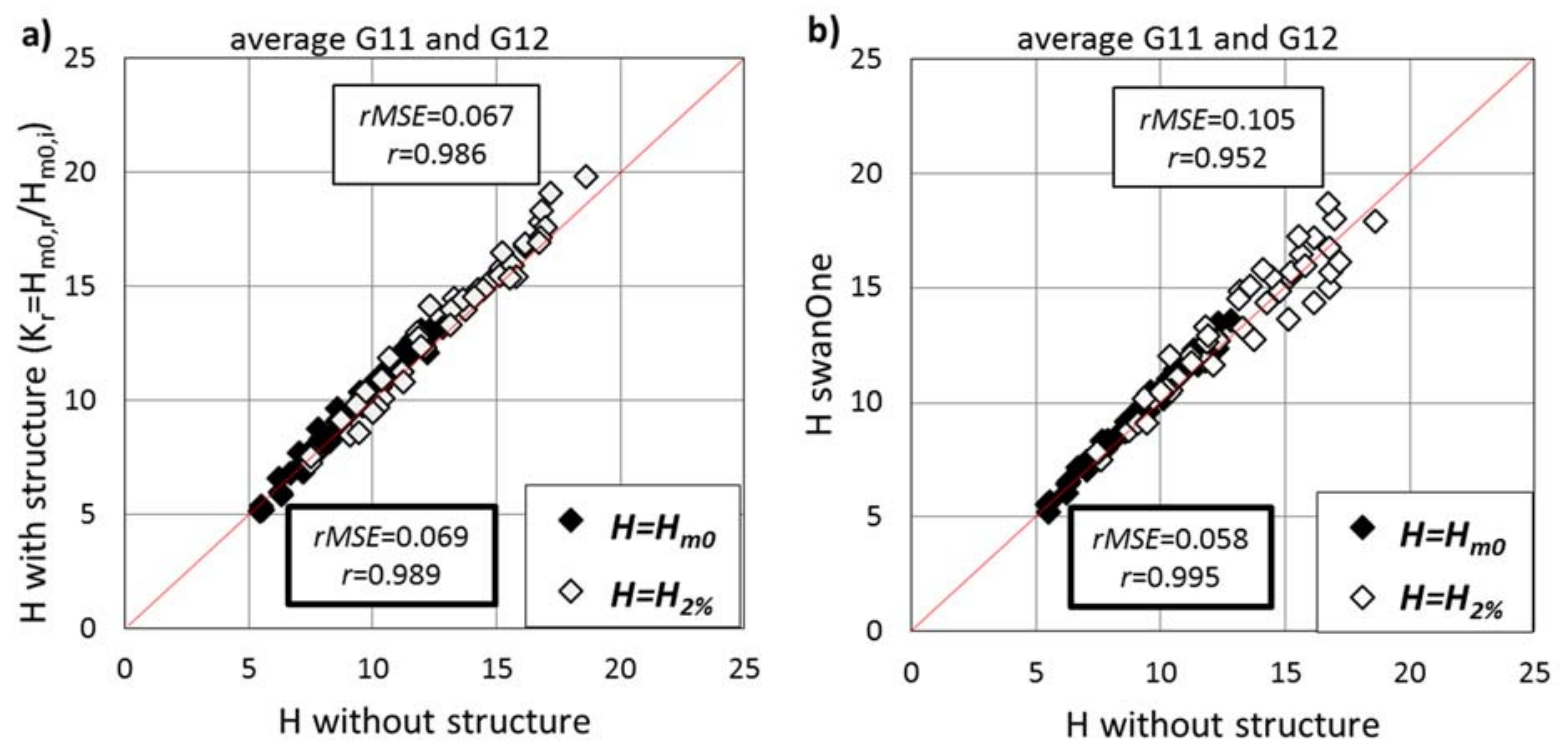

Fig. 4. Comparison of experimental incident $H_{m 0}$ and $H_{2}$ without the structure and (a) experimental measurements with the structure obtained using $K_{r}$ and (b) SwanOne estimations.

Both experimental results and numerical simulations showed a variation in wave height distributions along the wave flume. $H_{m o}$ and $H_{2}$ increased or dereased along the flume due to shoaling and breaking processes, depending on test characteristics. In the wave generating zone, waves were Rayleigh-distributed $\left(H_{2 \%} / H_{m 0} \approx 1.4\right)$. However, the ratio of $H_{2 \%} / H_{m o}$ close to the breakwater model (G11 and G12) varied from 1.2 to 1.5 in physical tests and numerical simulations. Figs. $5 a$ and $5 b$ show the values of $H_{m 0}$ and $H_{2 \%}$ introduced in SwanOne at the position of G1 (wave generating zone) and the average estimated by SwanOne at the positions of G11 and G12 (model zone), as a function of the water depth at the toe, $h_{s}$, and the surf similarity parameter, $\xi_{p}$. Lower $h_{s}$ and $\xi_{p}$ led to lower values of $H_{m 0}$ and $H_{2 \%}$ at the toe of the structure. Fig. 6 shows the average estimations of $H_{m 0}$ compared to those of $H_{2} \%$, given by SwanOne at the G11 and G12 positions; lower $h_{s}$ led to lower values of $H_{2} \% / H_{m 0}$ at the toe of the structure. 
a)

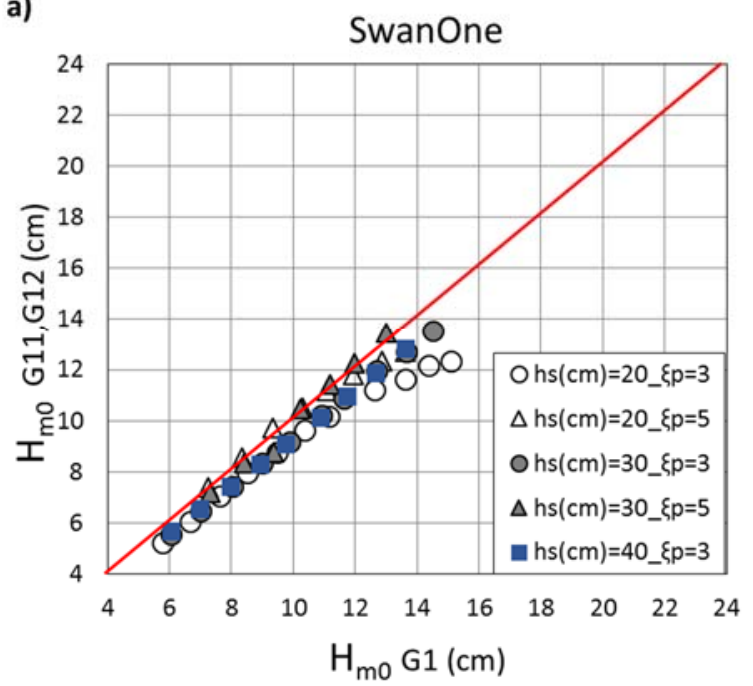

b)

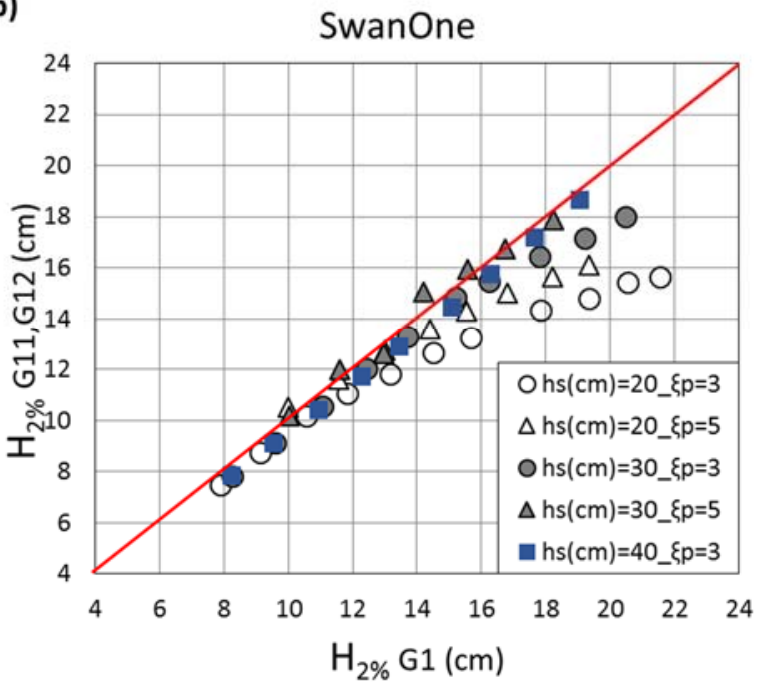

Fig. 5. Wave height values given by SwanOne at the position of G1 (wave generating zone) versus the average of G11 and G12 (model zone): (a) $H_{m 0}$ and (b) $H_{2 \%}$.

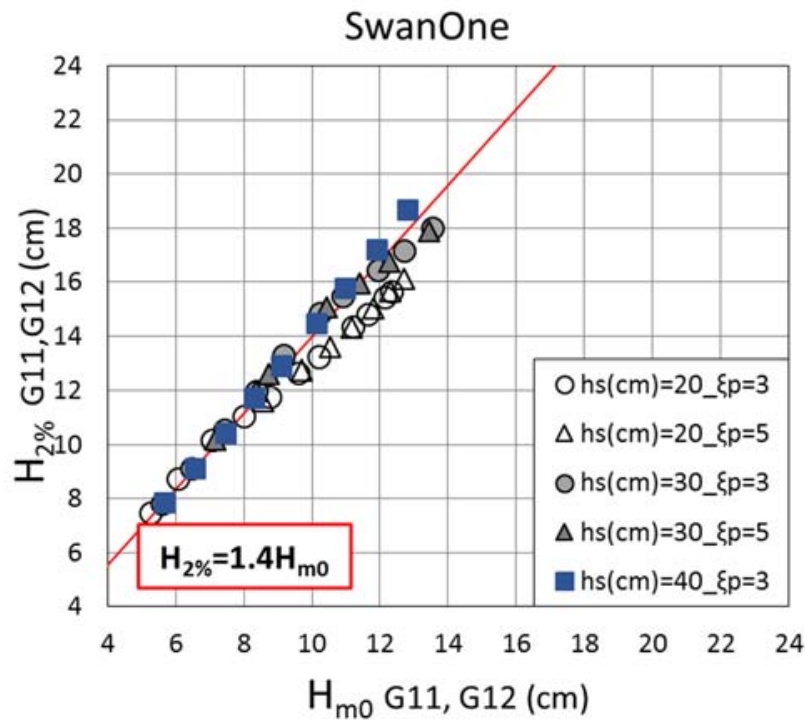

Fig. 6. Comparison of the mean values of $\mathrm{H}_{m 0}$ and $\mathrm{H}_{2 \%}$ estimated by the SwanOne at the G11 and G12 positions.

\subsection{Armor Damage analysis}


As mentioned in Section 3.1, armor damage was characterized after each test using the virtual net and visual counting methods. Cumulative rocks displaced from the armor layer were counted after each test run to calculate the equivalent dimensionless damage parameter, $S_{e}$, and the visual dimensionless damage parameter, $S_{v}$. Following the criteria given by Losada et al. [37] and Vidal et al. [38], four qualitative armordamage levels were considered:

1. Initiation of Damage (IDa), when the upper armor layer has lost some units.

2. Initiation of Iribarren's Damage (IIDa), when damage in the upper area has spread over an area large enough to permit the extraction of units from the bottom armor layer.

3. Initiation of Destruction (IDe), when at least one unit from the bottom armor layer has been removed and the filter is clearly visible.

4. Destruction (De), when several units have been removed from the filter layer. Figs. $7 \mathrm{a}$ and $7 \mathrm{~b}$ provide the stability numbers, $N_{s}=H /\left(\Delta D_{n 50}\right)$, for Initiation of Damage and Initiation of Destruction, respectively, obtained in the experiments when considering $H=H_{m o}$ and $H=H_{2} \%$ close to the model (G11 and G12) for test measurements and SwanOne estimations. The IDa and IDe limits for double-layer rock armors did not depend on wave steepness at $G 11$ and $G 12, s_{0 p, G 11-G 12}=2 \pi H_{m 0} / g T_{p}^{2}$. When using $H=H_{m 0}$, $N_{s}($ IDa $) \approx 1.38$ and $N_{s}($ IDe $) \approx 2.09$; when using $H=H_{2 \%}, N_{s}($ IDa $) \approx 1.95$ and $N_{s}($ IDe $) \approx 2.89$. 
a)

IDa

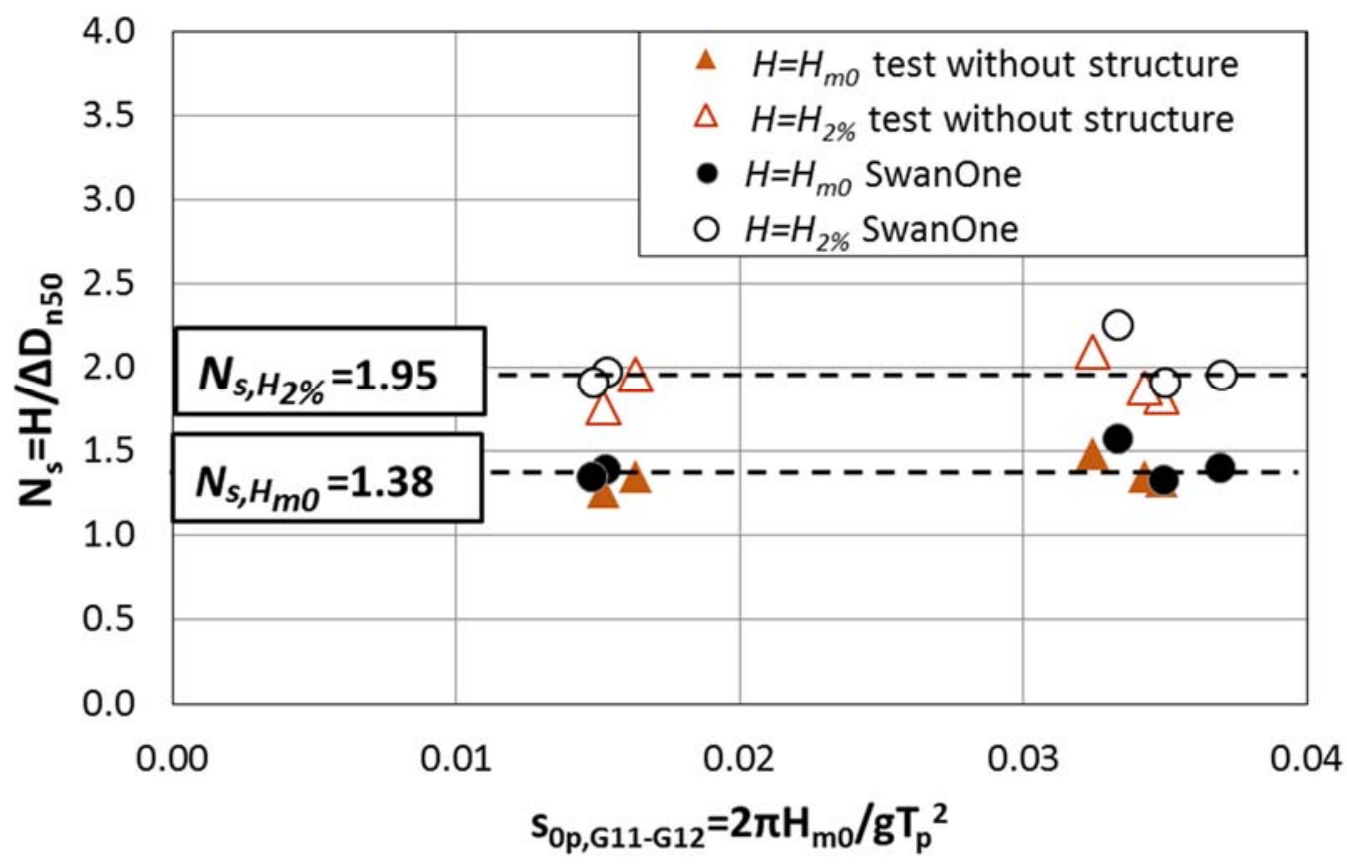

b)

IDe

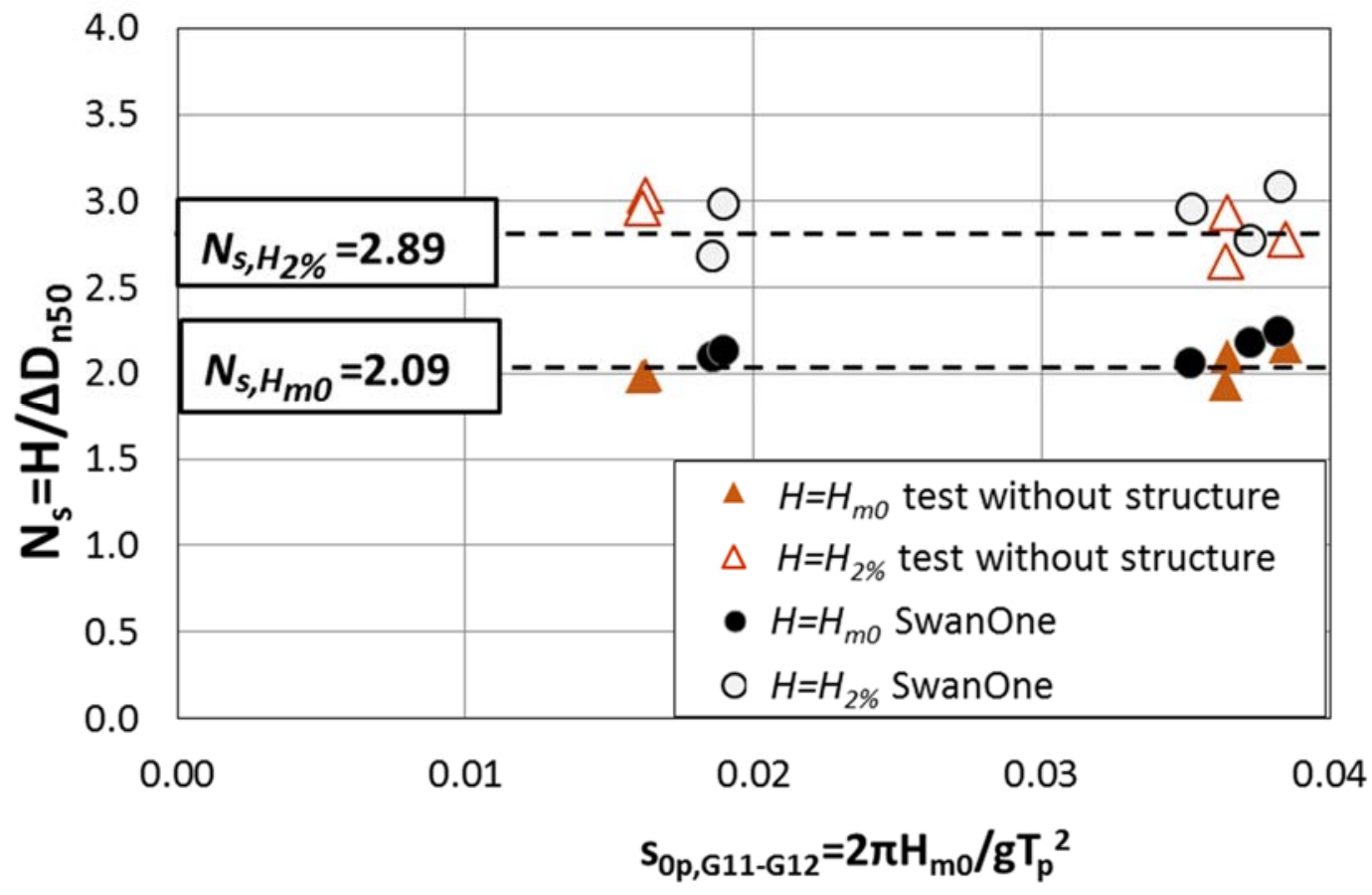

Fig. 7. Stability numbers considering waves at G11 and G12 for (a) Initiation of Damage and (b) Initiation of Destruction. 
Table 3 provides the $S_{e}$ obtained with the virtual net method and the $S_{v}$ obtained using the visual counting method for the Initiation of Damage, Initiation of Iribarren Damage and Initiation of Destruction limits after each test series. Fig. 8 shows the armor damage measurements with both methods after each test run.

Table 3. Dimensionless armor damage measurements using the virtual net and visual counting methods.

\begin{tabular}{lccc}
\hline \multirow{2}{*}{ Series } & \multirow{2}{*}{ Damage level } & \multicolumn{2}{c}{ Armor damage measurements } \\
\cline { 3 - 4 } & & Virtual net $\left(S_{e}\right)$ & Visual counting $\left(S_{v}\right)$ \\
\hline 1 & IDa & 0.3 & 0.3 \\
& IIDa & 2.7 & 2.7 \\
& IDe & 6.4 & 6.5 \\
\hline 2 & IDa & 0.6 & 0.6 \\
& IIDa & 1.9 & 1.8 \\
& IDe & 4.4 & 3.8 \\
\hline 4 & IDa & 0.7 & 0.5 \\
& IIDa & 1.3 & 1.3 \\
& IDe & 7.0 & 7.1 \\
\hline 5 & IDa & 0.5 & 0.5 \\
& IIDa & 1.7 & 1.7 \\
& IDe & 7.4 & 7.5 \\
\hline & IDa & 0.3 & 0.2 \\
& IIDa & 1.5 & 1.5 \\
& IDe & 6.0 & 6.0 \\
\hline
\end{tabular}




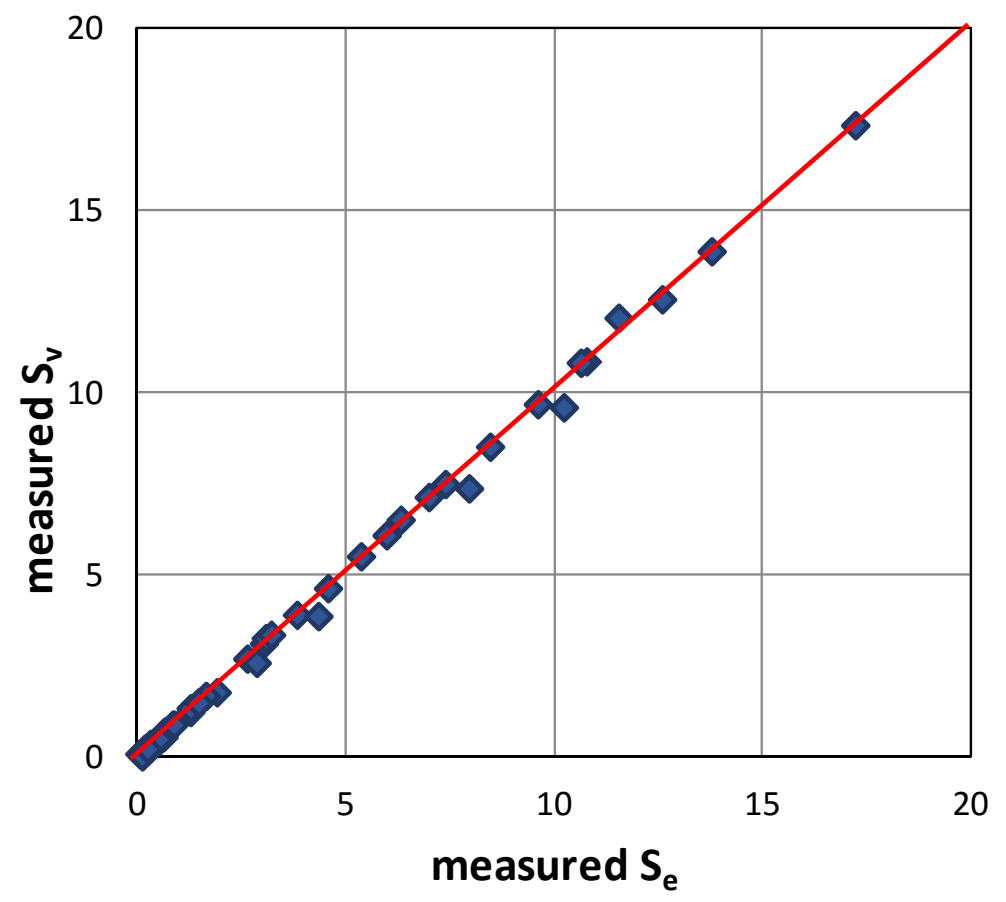

Fig. 8. Comparison of the equivalent dimensionless damage parameter, $S_{e}$, and the visual dimensionless damage parameter, $S_{v}$, measured after each test run.

The virtual net and visual counting methods gave similar results $\left(S_{e} \approx S_{v}\right)$ as most armor damage was caused by unit extractions only. $S_{e}$ was finally used in this study to characterize armor damage. Fig. 9 shows the $S_{e}$ measured after each test run as a function of the stability number, $N_{s}=H /\left(\Delta D_{n 50}\right)$, when considering $H=H_{m 0}$ and $H=H_{2} \%$ for test measurements (Figs. 9a and 9b) and SwanOne estimations (Figs. 9c and 9d). $S_{e}$ showed a potential relationship with $N_{s}$. From a qualitative point of view, Fig. 9 shows that $H_{m 0}$ is a better wave height descriptor than $H_{2 \%}$ for the armor failure function, because it leads to lower estimation errors. Furthermore, the experimental wave measurements showed slightly larger estimation errors than numerical simulations using SwanOne. 


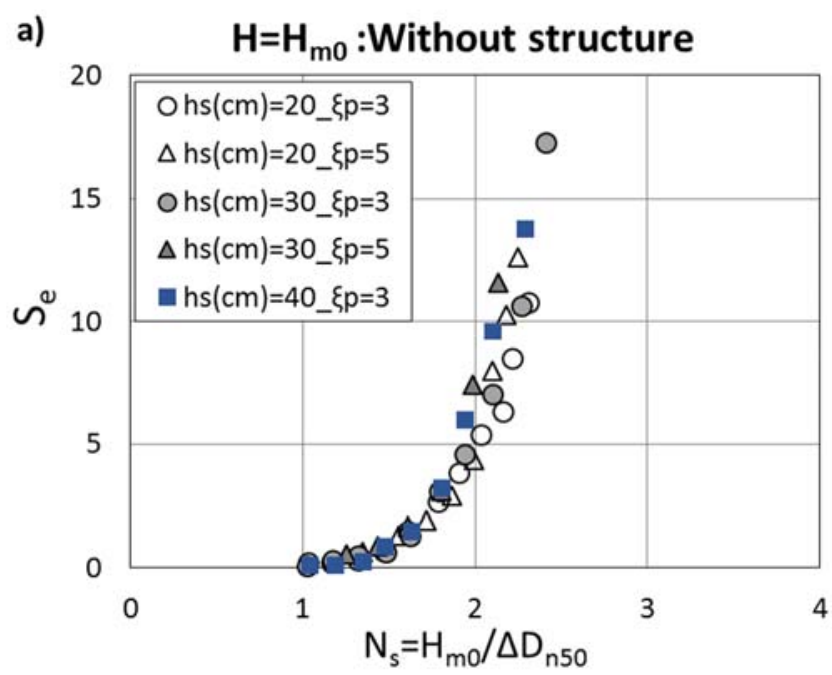

c)

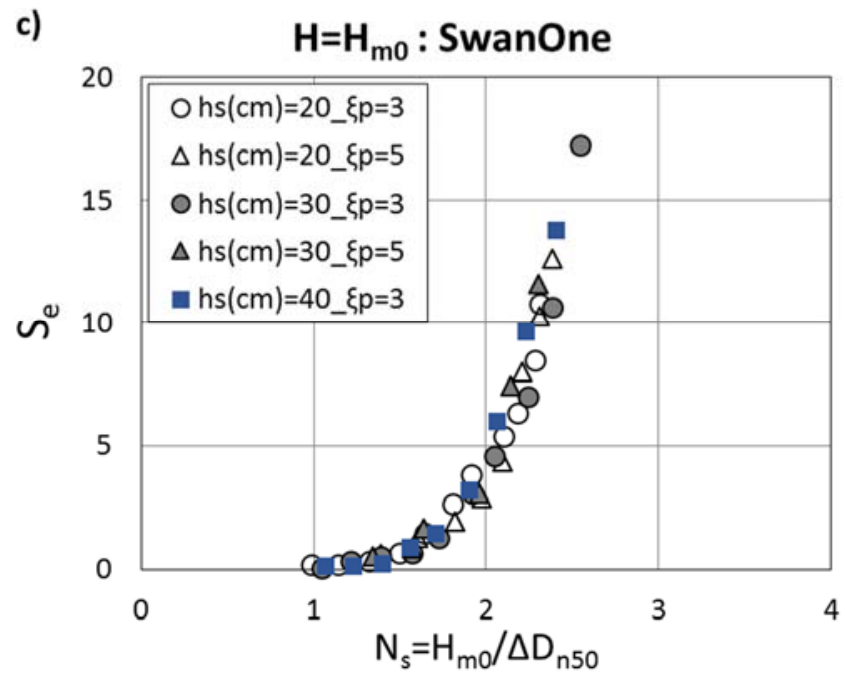

b)

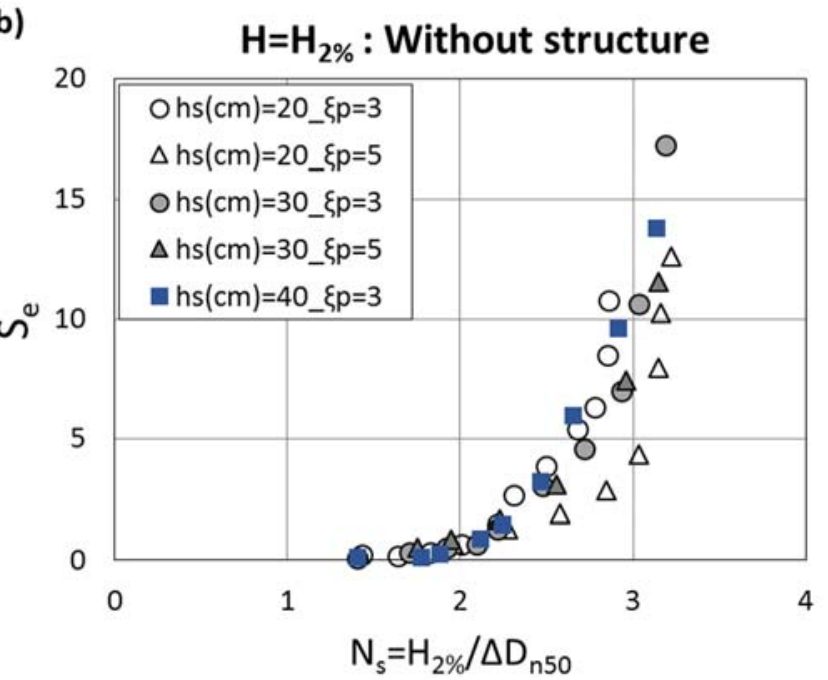

d)

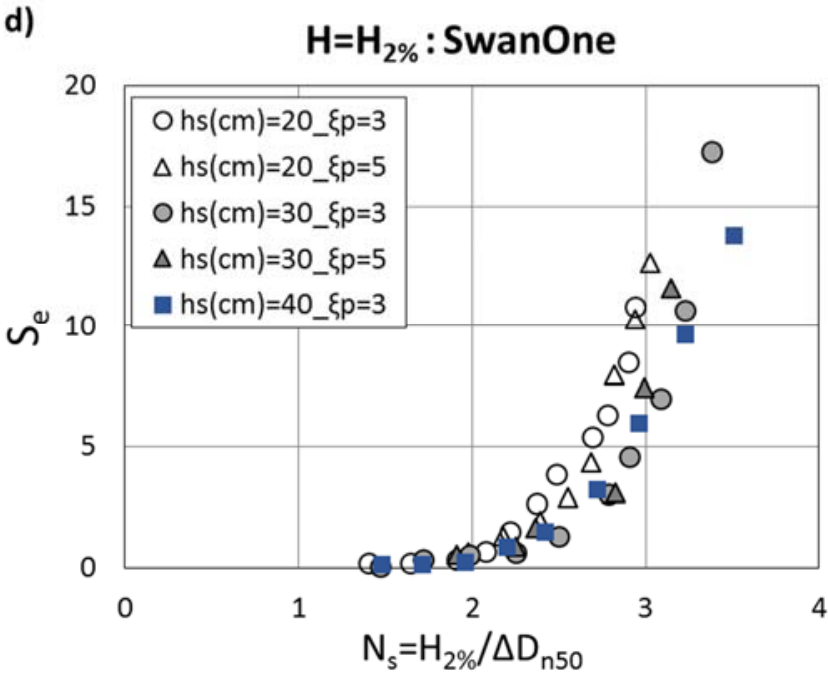

Fig. 9. Measured armor damage, $S_{e}$, as a function of the stability number, $N_{s}=H /\left(\Delta D_{n 50}\right)$, when using (a) measured $H=H_{m o}$ without the structure, (b) measured $H=H_{2} \%$ without the structure, (c) estimated $H=H_{m 0}$ by SwanOne, and (d) estimated $H=H_{2}$ by SwanOne.

\section{A new hydraulic stability formula}

Based on the results described previously, a new formula was developed to include the most relevant parameters affecting the hydraulic stability of rock armors in breaking wave conditions, with $m=1 / 50, \cot \alpha=1.5,0.018 \leq \mathrm{s}_{0 p} \leq 0.049,1.0 \leq H_{m 0} / \Delta D_{n 50} \leq 2.5$ and $3.75 \leq h_{s} / \Delta D_{n 50} \leq 7.50$. Three explicative variables for armor damage, $S_{e}$, were initially 
considered: (1) stability number, $N_{s}=H /\left(\Delta D_{n 50}\right)$, (2) local wave steepness based on the mean wave length close to the model (G11 and G12), $s_{m}=H_{m o} / L_{m}$, and (3) water depth at the toe of the structure, $h_{s}$. The initial model considered to estimate armor damage was:

$S_{e}=k_{1}\left(\frac{H}{\Delta D_{n 50}}\right)^{k 2}\left(s_{m}\right)^{k 3}\left(h_{s}\right)^{k 4}$

in which $k_{1}, k_{2}, k_{3}$ and $k_{4}$ were fitting parameters and $H=H_{m o}$ or $H=H_{2} \%$.

A t-student test ( $5 \%$ level of significance) discarded $s_{m}$ and $h_{s}$ as significant explicative variables. Thus, Eq. (10) was re-written as:

$S_{e}=k_{1}\left(\frac{H}{\Delta D_{n 50}}\right)^{k_{2}}$

in which $k_{1}$ and $k_{2}$ were calibrated using wave measurements and SwanOne estimations for $H=H_{m 0}$ and $H=H_{2}$. The results were $k_{1}=0.083$ and $k_{2}=6.0$ for $H=H_{m 0}$, and $k_{1}=0.012$ and $k_{2}=6.0$ for $H=H_{2} \%$ when considering wave measurements without the structure. For SwanOne estimations, the results were $k_{1}=0.066$ and $k_{2}=6.0$ for $H=H_{m 0}$, and $k_{1}=0.010$ and $k_{2}=6.0$ for $H=H_{2}$. The goodness of fit was very good in the four cases. However, SwanOne estimations were finally recommended because they are easy to use and showed a slightly better goodness of fit so as to obtain a new formula valid in the range $0.018 \leq \mathrm{s}_{0 p} \leq 0.049,1.0 \leq H_{m 0} / \Delta D_{n 50} \leq 2.5$ and $3.75 \leq h_{s} / \Delta D_{n 50} \leq 7.50$.

Fig. 10a shows the armor damage $S_{e}$ measured in laboratory tests, compared to the stability number for both $H=H_{m 0}$ (closed dots) and $H=H_{2} \%$ (open dots) estimated by SwanOne at the positions of G11 and G12 (average value). Fig. 10b compares the $S_{e}$ measured in laboratory tests with the $S_{e}$ estimated by Eq. (11) when using $H=H_{m o}$ (closed 
dots) and $H=H_{2} \%$ (open dots), estimated by SwanOne at the positions of G11 and G12 (average value). The agreement between measured and estimated $S_{e}$ was good for both $H=H_{m 0}$ and $H=H_{2 \%}$; however, errors were lower for $H=H_{m o}(r M S E=0.022$ and $r=0.989)$ than $H=H_{2 \%}(r M S E=0.151$ and $r=0.922)$.
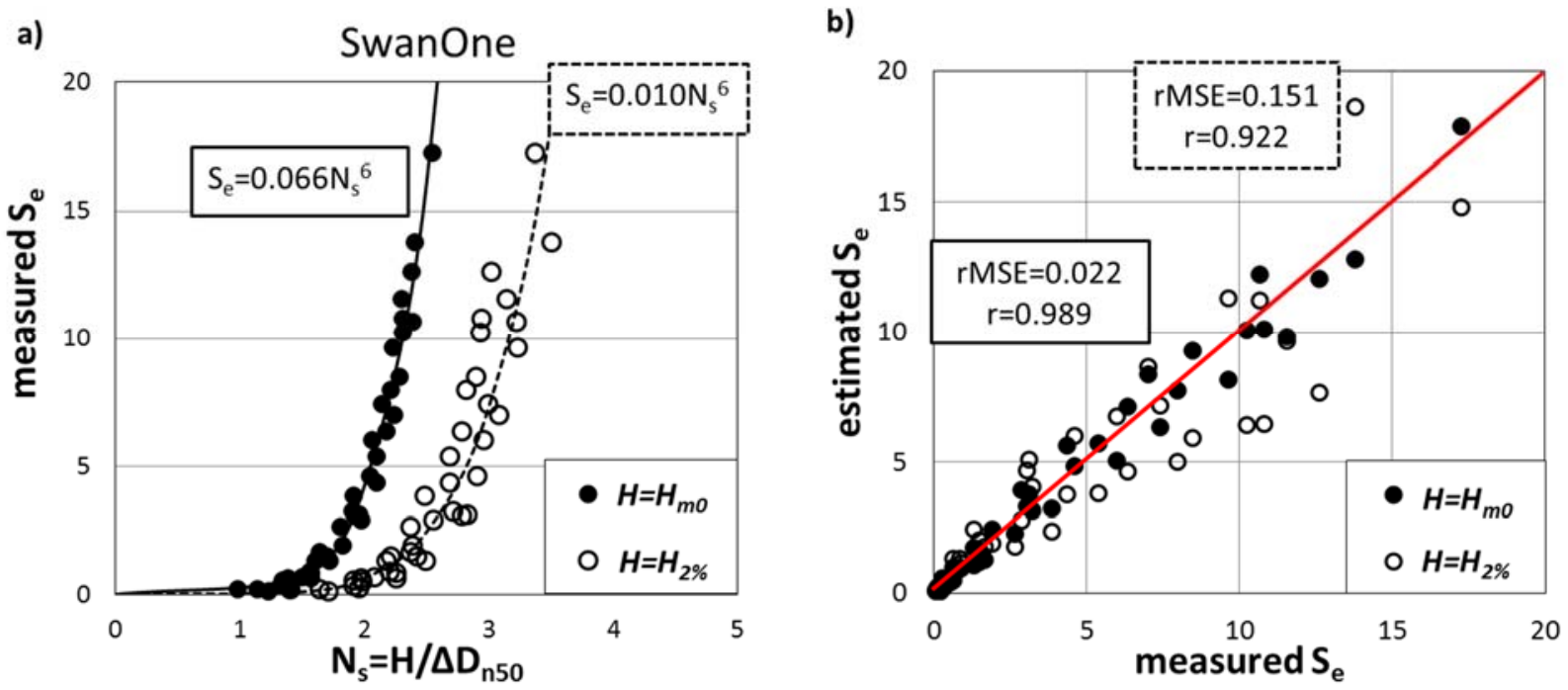

Fig. 10. (a) Measured armor damage, $S_{e}$, as a function of the stability number, $N_{s}=H /\left(\Delta D_{n 50}\right)$, for $H=H_{m 0}$ and $H=H_{2}$ estimated by SwanOne, and (b) measured $S_{e}$ versus estimated $S_{e}$ by Eq.(11).

In order to analyze the variability of the errors when considering $H=H_{m 0}$ or $H=H_{2} \%$, a bootstrap resample technique was used following the methodology described by Van Gent et al. [40]. A bootstrapping resample is a random selection of $N$ data taken from the original $N$ dataset, with the probability $1 / N$ that a particular datum is selected each time. In this study, 1000 resamples were considered with $S_{e}$ estimated by Eq. (11) with $H=H_{m 0}$ and $H=H_{2} \%$. Fig. 11 shows $r M S E$ discrete frequency histograms of $S_{e}$ when using Eq. (11) with $H=H_{m 0}$ and $H=H_{2 \%}$. The $r M S E$ distributions followed a normal distribution 
when using both $H=H_{m 0}$ and $H=H_{2} \%$. The errors were lower for $H=H_{m 0}$ than $H=H_{2} \% ; H_{m 0}$ was finally selected in this study to describe the armor damage, $S_{e}$.

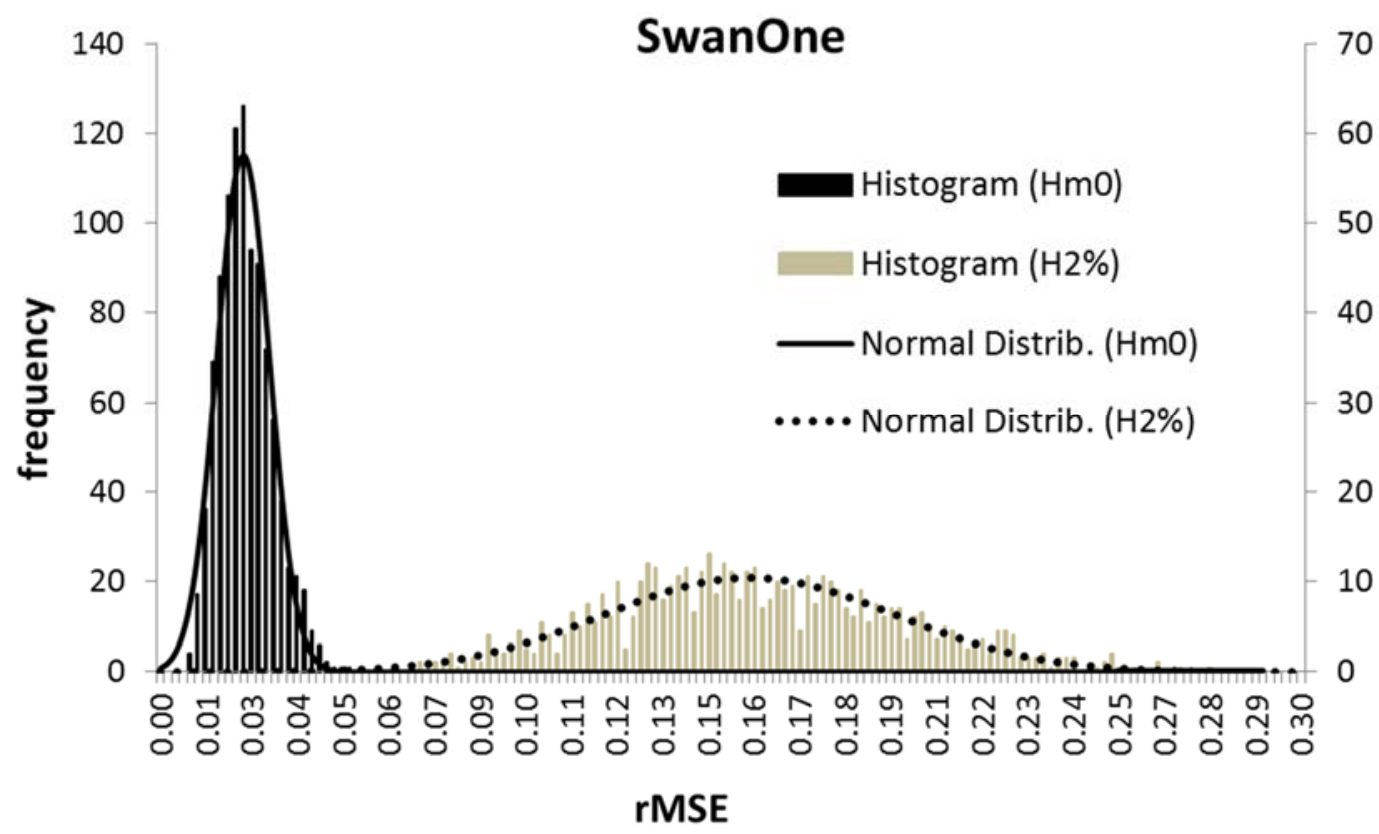

Fig. 11. rMSE frequency histograms of estimated $S_{e}$ when using Eq. (11) with $H=H_{m o}$ and $H=H_{2 \%}$.

The previous analysis was conducted with SwanOne estimations at the position of the wave gauges $\mathrm{G} 11$ and $\mathrm{G} 12$, situated at a distance of $0.8 \mathrm{~m}$ and $0.5 \mathrm{~m}$ seaward from the structure toe, respectively. In order to identify the optimum location to determine $H_{m o}$ to describe armor damage, this characteristic wave height was also estimated by the SwanOne model at five points: just at the toe of the structure, and at a distance of $h_{s}$, $2 h_{s}, 3 h_{s}$ and $4 h_{s}$ seaward from the structure toe. Table 4 shows the calibrated values of $k_{1}$ and $k_{2}$ in Eq. (11) when using $H_{m o}$ estimated by SwanOne at the specified locations $\left(d^{*}=0, d^{*}=h_{s}, d^{*}=2 h_{s}, d^{*}=3 h_{s}\right.$ and $\left.d^{*}=4 h_{s}\right)$, where $d^{*}$ is the distance from the structure toe. The $r M S E$ and the $r$ values between measured and estimated armor damage $S_{e}$ using Eq. (11) are also given in Table 4. 
Table 4. Calibrated values of $k_{1}$ and $k_{2}$ in Eq. (11) for $H_{m o}$ estimated by SwanOne at a seaward distance from the toe of the structure, $d^{*}$, and $r M S E$ and $r$ values for measured and estimated $S_{e}$ using Eq. (11).

\begin{tabular}{lllll}
\hline $\begin{array}{l}\text { Seaward distance from } \\
\text { the structure toe, } d^{*}\end{array}$ & $k_{1}$ (Eq. 11) & $k_{2}$ (Eq. 11) & $r M S E$ & $r$ \\
\hline 0 (TOE) & 0.071 & 6.0 & 0.031 & 0.984 \\
$h_{s}$ & 0.069 & 6.0 & 0.026 & 0.987 \\
$2 h_{s}$ & 0.068 & 6.0 & 0.024 & 0.987 \\
$3 h_{s}$ & 0.066 & 6.0 & 0.023 & 0.988 \\
$4 h_{s}$ & 0.065 & 6.0 & 0.024 & 0.987 \\
\hline
\end{tabular}

The best agreement was found for $\mathrm{H}_{m o}$ estimated at a distance of three times the water depth at the toe $\left(3 h_{s}\right)$ seaward from the toe of the structure ( $r M S E=0.023$ and $r=0.988$ ). This distance approximately corresponds to the distance of $5 H_{s}$ proposed by Goda [41] and recommended by Melby [42] to determine wave parameters, when considering $H_{s}$ in breaking wave conditions. Thus, $H_{m 0}$ estimated at a distance of $d^{*}=3 h_{s}$ seaward from the structure toe was finally proposed in this study to describe the armor damage, $S_{e}$, given by Eq. (11) with $k_{1}=0.066$ and $k_{2}=6.0$.

Note that for bottom slope $m=1 / 50$, the differences in the range $0 \leq d^{*} \leq 4 h_{s}$ are low. However, with steeper bottom slopes, significant differences may be observed when considering different points to estimate the design wave parameters in the wave breaking zone. Furthermore, it is convenient to highlight that these results are strictly valid in the prescribed range of applicability, with constant $2 \%$ sea bottom slope 
$(m=1 / 50)$, constant water depth at the toe $\left(h_{s}\right)$ and unidirectional waves perpendicular to the coast (2D tests). Practical applications usually involve directional waves (3D) and tides, storm surges and other waves and processes which may induce relevant changes in water levels and bottom profiles, and they must be taken into account when selecting the design parameters.

\subsection{Confidence intervals for the new hydraulic stability formula}

Assuming a Gaussian error distribution, the $90 \%$ confidence interval for the armor damage estimation given by Eq. (11) with $H=H_{m 0}$ estimated at a distance of $3 h_{s}$ seaward from the structure toe, $k_{1}=0.066$ and $k_{2}=6.0$ is:

$S_{e} \mid \begin{aligned} & 95 \% \\ & 5 \%\end{aligned}=S_{e} \pm 1.64 \cdot \sqrt{\operatorname{Var}(\varepsilon)}$

where $S_{e}$ is given by Eq. (11) and $\operatorname{Var}(\varepsilon)$ is the variance of the estimation errors. $\operatorname{Var}(\varepsilon)$ was not considered as constant but rather as a linear function of $S_{e} . S_{e}$ data were ordered and grouped in nine data sets as shown in Fig. 12. The MSE was calculated for each data set (closed squares in Fig. 12). As the MSE increases with increasing $S_{e}$, the variance of the errors was estimated by:

$\operatorname{Var}(\varepsilon)=0.1 \cdot S_{e}$

where $S_{e}$ is given by Eq. (11) with $H=H_{m 0}, k_{1}=0.066$ and $k_{2}=6.0$. The $90 \%$ confidence interval is given by:

$S_{e} \mid{ }_{5 \%}^{95 \%}=S_{e} \pm 1.64 \cdot \sqrt{\left(0.1 \cdot S_{e}\right)}=S_{e} \pm 0.52 \cdot \sqrt{S_{e}}$ 


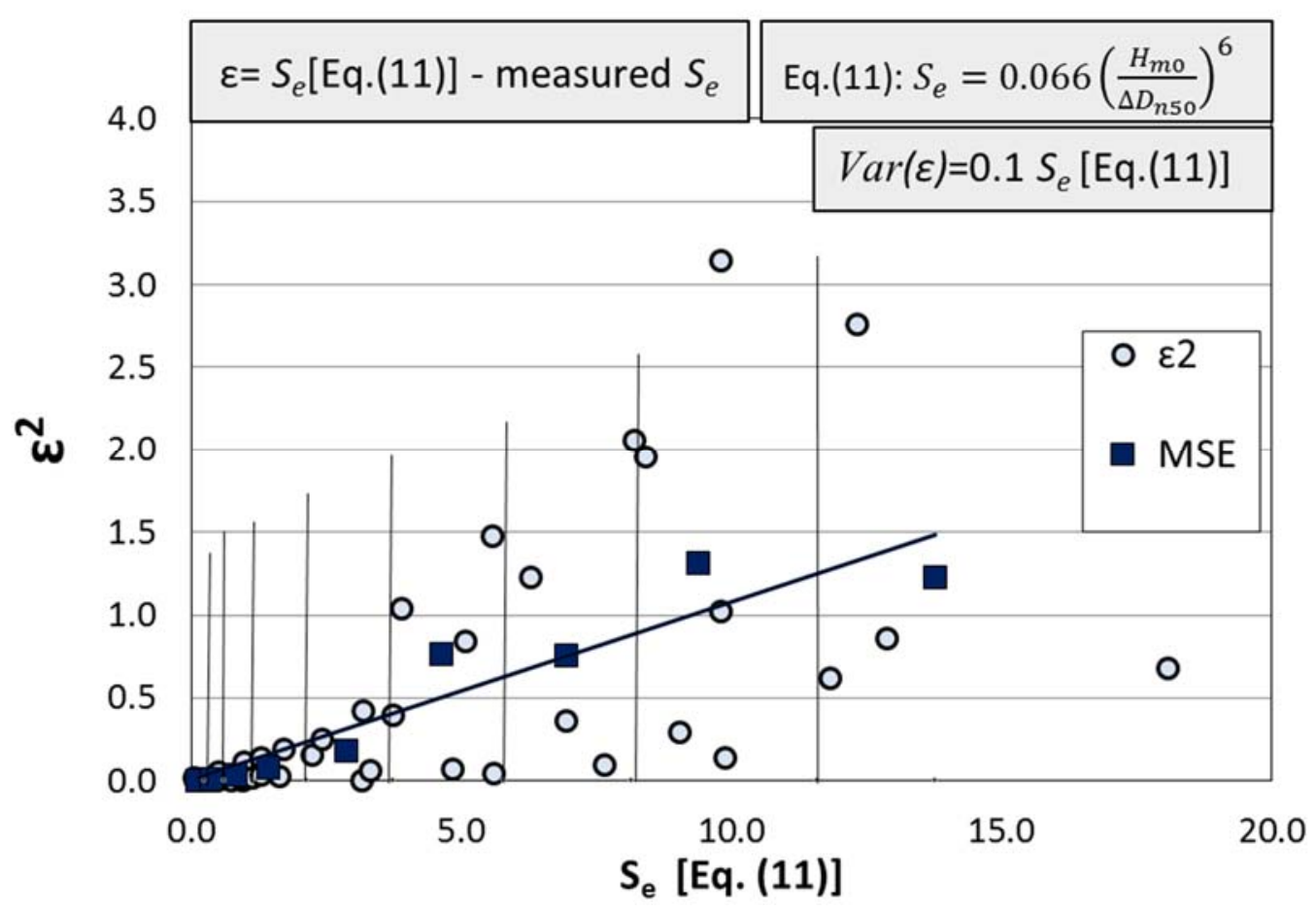

Fig. 12. Squared armor damage errors as a function of the $S_{e}$ estimated by Eq. (11) with $H=H_{m 0}$ obtained at a distance of $3 h_{s}$ seaward from the structure toe, $k_{1}=0.066$ and $k_{2}=6.0$.

Fig. 13 compares measured $S_{e}$ and estimated $S_{e}$ given by Eq. (11) with $H=H_{m 0}$, as well as the $90 \%$ confidence interval given by Eq. (14). The rMSE and the $r$ were used to determine the goodness of fit between the values of $S_{e}$ measured in tests and the $S_{e}$ given by Eq. (11). The $r M S E=0.023$ indicated the proportion of variance of $S_{e}$ not explained by Eq. (11) and $r=0.988$, the degree of correlation between measured and estimated values of $S_{e}$. 


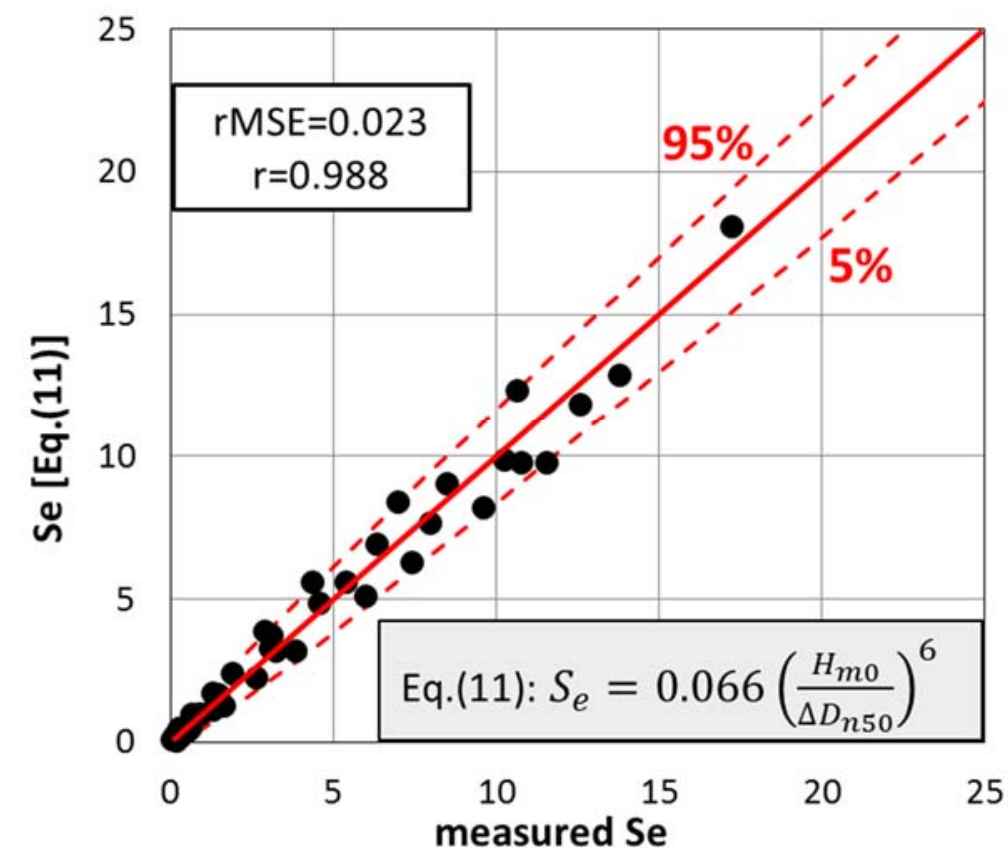

Fig. 13. Measured $S_{e}$ versus estimated $S_{e}$ given by Eq. (11) using $H=H_{m 0}$ estimated at a distance of $3 h_{s}$ seaward from the structure toe, and the $90 \%$ confidence intervals given by Eq. (14).

5.2. Comparison of the experimental results and new formula with existing formulas

As mentioned in Section 2, different formulas have been proposed to estimate armor damage (Eqs. (1) to (5)). Although some of them were developed for non-breaking wave conditions, a comparison was made between the armor damage measured in this study and the predictions given by Eqs. (1) to (5), which can be re-written in terms of dimensionless armor damage, $S$. To this end, the equivalent armor damage $S_{e} \approx S_{v}$, measured in the laboratory tests, was related to the dimensionless armor damage $S=S_{e}$ used in these equations. 
In this study, the model was attacked by successive wave runs having increasing $\mathrm{H}_{m o}$ and $T_{p}$, and cumulative damage, $S_{e}$, was measured. Note that Eq. (11) proposed in this study implicitly considers the cumulative damage of minor storms attacking the breakwater in breaking wave conditions for a given wave steepness and water depth. To compare these results with those given by Eqs. (2a), (2b), (4a), (4b) and (5), it was necessary to apply a method to estimate the evolution of armor damage in a succession of sea states. In this study, the method proposed by Van der Meer [43] was used, with a permeability value of $P=0.4$ (permeable filter and core):

Step 1. For the first sea state composed of $N_{z}$ waves, Eqs. (2a), (2b), (4a), (4b) and (5) were directly used to estimate the dimensionless armor damage, $S$, using the wave parameters estimated by the SwanOne model.

Step 2. For the next sea state, an equivalent number of waves, $N_{z}{ }^{*}$, which produced the damage estimated in the previous sea state was computed using Eqs. (2a), (2b), (4a), (4b) and (5) with the new sea state parameters. The equivalent number of waves, $N_{z}{ }^{*}$, was added to the number of waves in the present sea state to calculate the final damage using Eqs. (2a), (2b), (4a), (4b) and (5).

Step 3. If necessary, step 2 was repeated.

Eq. (1), which is not dependent on storm duration, was applied as indicated in Appendix A using the $K_{D}$ value proposed by USACE [4] for breaking waves and double-layer randomly-placed rough-angular rock armor $\left(K_{D}=3.5\right)$ with $H=H_{s}$, and also the $K_{D}$ value proposed by USACE [5] for breaking waves $\left(K_{D}=2.0\right)$ with $H=H_{1 / 10}$. 
Figs. $14 \mathrm{a}$ and $14 \mathrm{~b}$ show the linearized measured armor damage, $S^{1 / 6}$, and the estimations of $S^{1 / 6}$ given by Eqs. (1), (5) and (11), which are not dependent on wave period (Fig. 14a), and by Eqs. (2a), (2b), (3), (4a) and (4b), which do depend on wave period (Fig. 14b). The 90\% confidence interval of Eq. (11) proposed in this study, using $H=H_{m 0}$ estimated by SwanOne at a distance of $3 h_{s}$ seaward from the structure toe, is also depicted in Figs. 14a and 14b. The significant wave height $H_{s}=H_{1 / 3}$ used in Eqs. (3) and (5) and Eq. (1) when considering $H=H_{s}$ (USACE [4]), was obtained using the CWD method proposed by Battjes and Groenendijk [11]. For Eqs. (1) and (5), $H_{s}$ was calculated at the toe of the structure; for Eq. (3), $H_{s}$ was calculated at distances of $5.7 h_{s}$ and $7.6 h_{s}$ seaward from the structure toe as in the tests conducted by Melby and Kobayashi [7]. $H_{s}$ was replaced by $H_{2 \%} / 1.4$ in Eqs. (2a) and (2b), as recommended by Van der Meer [6] for breaking wave conditions, with $H_{2 \%}$ obtained from $H_{m 0}$ estimated by SwanOne at the toe of the structure. $H_{1 / 10}$ used in Eq. (1) by USACE [5] was also obtained at the toe of the structure from SwanOne estimations (note that $H_{1 / 10} \approx 1.27 H_{s}$ is only valid when assuming a Rayleigh distribution).
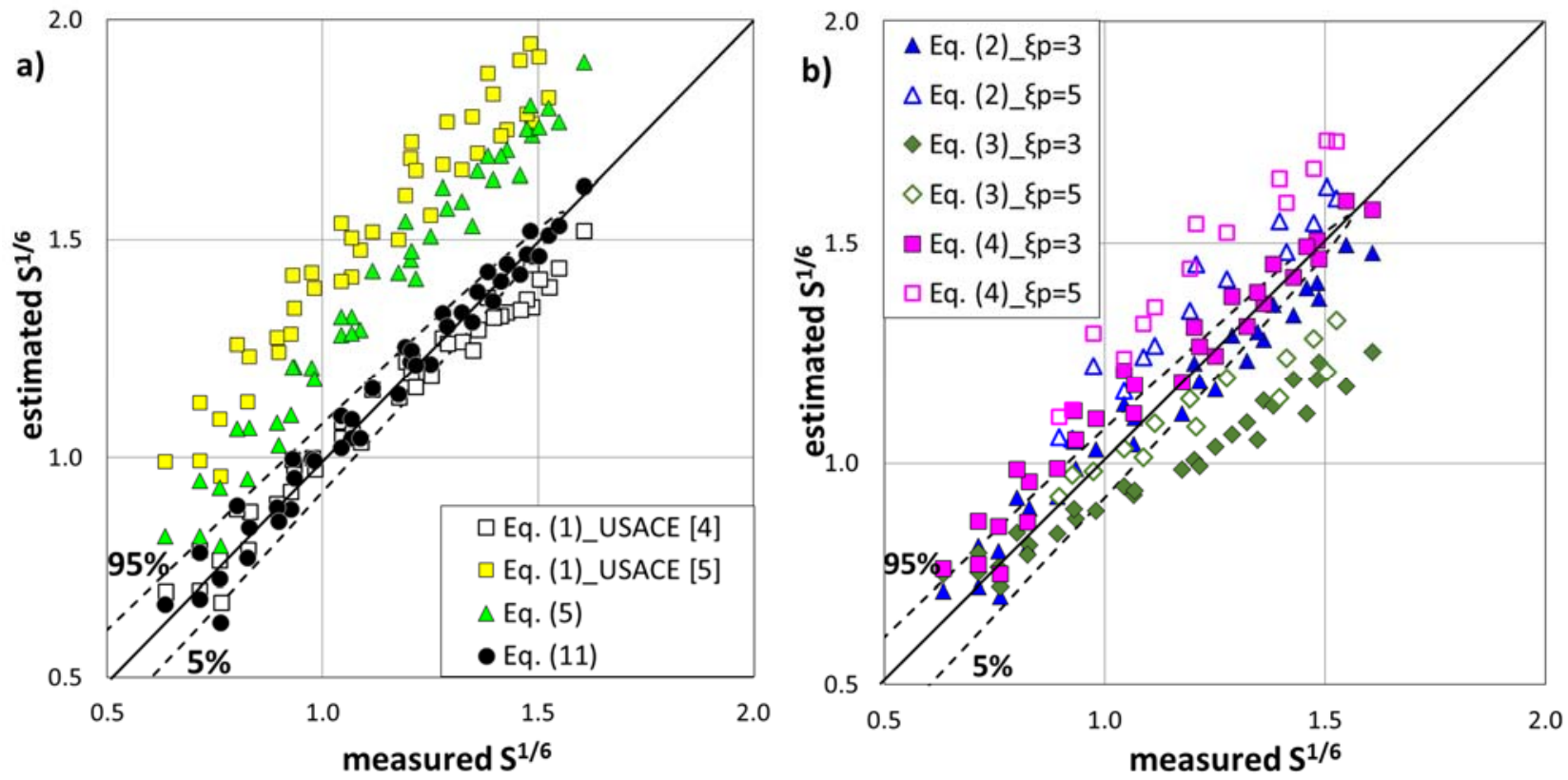
Fig. 14. Linearized measured armor damage, $S^{1 / 6}$, versus estimations of $S^{1 / 6}$ given by existing formulas and $90 \%$ confidence interval of Eq. (11).

Fig. 14a clearly differentiates predictions given by Eq. (1) when using USACE [4] and USACE [5]. USACE [4] gave fair predictions for low levels of armor damage and slightly underestimated high levels of armor damage. USACE [5] significantly overestimated armor damage for all damage levels (implicit safety factor much higher than 1.0). Eq. (1) was based on regular tests in non-breaking wave conditions.

Eq. (5) given by Van Gent et al. [8] overestimated armor damage. Eq. (5) was developed from irregular tests in breaking and non-breaking wave conditions with bottom slopes $m=1 / 30$ and $1 / 100$ and armor slopes $\cot \alpha=2$ and 4 , in which armor damage was measured with a surface profiler. Gómez-Martín [39] pointed out that significant differences may occur between armor damage measured with profiles and that measured with the visual counting method. Additionally, the method used to estimate cumulative damage in a succession of sea states, using a formula originally developed for a single sea state, may influence the results.

Eqs. (2a), (2b), (3), (4a) and (4b) gave higher armor damage estimations for $\xi_{p}=5.0$ than for $\xi_{p}=3.0$. For $\xi_{p}=5.0$, Eqs. (2a) and (2b) and Eqs. (4a) and (4b) overestimated armor damage; for $\xi_{p}=3.0$, Eqs. (2a) and (2b) slightly underestimated armor damage for high damage levels, and Eqs. (4a) and (4b) slightly overestimated armor damage for low damage levels. Eqs. (2a) and (2b) were developed from irregular tests mostly in nonbreaking wave conditions and adapted to breaking wave conditions replacing $H_{s}$ by $H_{2 \%} / 1.4$, despite the ratio $H_{2 \%} / H_{s}=1.4$ being valid for a Rayleigh distribution. Eqs. (4a) and 
(4b) were obtained modifying Eqs. (2a) and (2b) based on tests from Van Gent et al. [8] to take into account the influence of the spectral shape through the spectral wave period $T_{m-1,0}$

Eq. (3) reported by Melby and Kobayashi [7] underestimated armor damage for high damage levels. Eq. (3) is valid for a bottom slope $m=1 / 20$ (which is steeper than those used to validate Eqs. (2a), (2b), (4a), (4b) and (11)), armor slope cot $\alpha=2$, stability number $1.6 \leq H_{s} / \Delta D_{n 50} \leq 2.5$, and relative water depth $2.0 \leq h_{s} / \Delta D_{n 50} \leq 2.6$.

Physical tests in this study were conducted on a bottom slope $m=1 / 50$, with armor slope $\cot \alpha=1.5$, wave steepness $s_{0 p}=0.018$ and 0.049 , stability number $1.0 \leq H_{m o} / \Delta D_{n 50} \leq 2.5$, and relative water depth $3.75 \leq h_{s} / \Delta D_{n 50} \leq 7.50$. The bottom slope $\mathrm{m}=1 / 50$ is within the range of Eqs. (4a), (4b) and (5). However, the armor slope $\cot \alpha=1.5$ is out of the range of validity of existing formulas for breaking wave conditions. Note that a method to estimate the equivalent numbers of waves was required to consider the cumulative damage caused by a succession of sea states when applying Eqs. (2a), (2b), (4a), (4b) and (5). Eq. (3) was also based on a method proposed by Melby [22] to consider cumulative damage; CIRIA/CUR/CETMEF [26] pointed out that this method gives lower damage values than Van der Meer's [43] approach.

When using Eqs. (1) to (5), one should take into consideration that most of them require knowing $H_{s}$ or $H_{2 \%}$ at the toe of the structure; however, these equations were validated with incident waves measured with gauges located at a certain distance from the toe. Eq. (11) proposed in this study was validated with waves estimated at a distance of $3 h_{s}$ seaward from the structure toe, as this distance seemed to be the optimum location to 
determine wave characteristics so as to estimate armor damage to rock armors in the breaking zone with a bottom slope $m=1 / 50$.

\section{Conclusions}

Although rubble mound breakwaters are generally constructed in breaking wave conditions, most hydraulic stability formulas are based on laboratory tests in nonbreaking wave conditions. Only Eqs. (3) to (5) were based on specific tests carried out in breaking wave conditions. However, they were validated with tests with armor slopes $\cot \alpha \geq 2.0$ and bottom slopes $m=1 / 20$ (Eq. 3 ) and $m=1 / 30$ and $1 / 100$ (Eqs. $4 a, 4 b$ and 5).

This study analyzes the hydraulic stability of rock armors with low or zero overtopping, slope $\cot \alpha=1.5$, packing density $\phi=1.26$, and a bottom slope $m=1 / 50$, based on physical tests conducted at the LPC-UPV wave flume. Within the ranges $0.018 \leq s_{0 p} \leq 0.049$, $1.0 \leq H_{m 0} / \Delta D_{n 50} \leq 2.5$ and $3.75 \leq h_{s} / \Delta D_{n 50} \leq 7.50$, Eqs. (11) and (14) are used to estimate equivalent dimensionless armor damage, $S_{e}$, considering the observed 6-power relationship between $S_{e}$ and the stability number, $N_{s}=H /\left(\Delta D_{n 50}\right)$. The local wave steepness at the model zone, $s_{m}=H_{m o} / L_{m}$, and the water depth at the toe of the structure, $h_{s}$, were discarded as significant explicative variables of $S_{e}$, with a level of significance of 5\%. Eq. (11) proposed in this study implicitly considers the cumulative armor damage of minor storms attacking the breakwater in breaking wave conditions for a given wave steepness and water depth.

Eqs. (11) and (14) were calibrated for $H=H_{m 0}$ and $H=H_{2} \%$, obtained from laboratory measurements and numerical simulations given by the wave transformation model SwanOne; $H_{m o}$ was a better wave descriptor for armor damage than $H_{2 \%}$. In order to 
know the optimum location to characterize the design spectral wave height attacking the structure, $H_{m o}$ was estimated using SwanOne at different seaward distances from the structure toe. The estimations of $H_{m 0}$ given by SwanOne at a distance of $3 h_{s}$ seaward from the structure toe were found to be the most adequate to characterize waves in the depth-induced breaking zone when $\mathrm{m}=1 / 50$.

The comparison between the armor damage measured in this study and the estimations given by existing armor stability formulas revealed a high dispersion of results. Compared to armor damage estimations given by Eq. (11), USACE [4] slightly underestimated high levels of armor damage while USACE [5] clearly overestimated armor damage. Eqs. (2a), (2b), (3), (4a) and (4b) estimated higher armor damage for $\xi_{p}=5.0$ compared to $\xi_{p}=3.0$. Eqs. ( $\left.2 a\right)$ and $(2 b)$ overestimated armor damage with $\xi_{p}=5.0$ and slightly underestimated armor damage with $\xi_{p}=3.0$. Eq. (3) underestimated armor damage while Eqs. (4a) and (4b) overestimated armor damage. Eqs. (2a), (2b), (4a), (4b) and (5), originally developed for a single design storm, were applied using the method proposed by Van der Meer [43] to estimate the cumulative armor damage in this study, and Eq. (3) was used considering the cumulative damage method developed by Melby [22]. These equations require knowing the design wave height at the toe of the structure, although waves were measured with gauges located at a certain distance seaward from the toe. In this study, the distance of $3 h_{s}$ seaward from the structure toe was found to be the most adequate location to determine the characteristic wave height, $H_{m 0}$, to estimate armor damage in Eq. (11). When dealing with breaking waves, it is necessary to clearly specify the exact location to estimate design wave parameters, especially for steep sea bottoms. 
Few hydraulic stability tests described in the literature have been carried out in breaking wave conditions. Given the large number of relevant variables and parameters to be taken into consideration, further research is required to fully characterize the hydraulic stability of rock armors in breaking wave conditions. Different armors and bottom slopes for a wider range of applicability should be tested. Wave gauges should be placed at distances from the structure toe proportional to water depth $\left(2 h_{s}, 3 h_{s}, 4 h_{s}\right.$, etc.).

\section{Acknowledgments}

The authors acknowledge the financial support from the Spanish Ministry of Economy and Competitiveness (grants BIA2012-33967 and BIA2015-70436-R). The first author was financially supported through the FPU program (Formación del Profesorado Universitario) funded by the Spanish Ministry of Education (Ministerio de Educación, Cultura y Deporte) FPU13/01872. The authors thank Debra Westall for revising the manuscript.

\section{Appendix A. Rock armor damage function based on data from USACE [4,}

\section{5]}

The methodology described in Medina et al. [19] has been followed in this study to relate Eq. (1) to different levels of dimensionless armor damage, $S$. To this end, the armor damage in percentage, D, provided by USACE $[4,5]$ for rough quarrystones as a function of $H / H_{D=O}$ was used, where $H$ is the wave height corresponding to damage $D$, and $H_{D=0}$ is the design wave height corresponding to $D=0-5 \%$. USACE [4] recommended $H=H_{s}$ and USACE [5] recommended $H=H_{1 / 10}$ (different implicit safety factors). 
The armor damage, D, was defined as the percentage of the volume of rocks displaced from the active zone of the armor. USACE [5: 7-211] defined the active zone as "the area which extends from the middle of the breakwater crest down the seaward face to a depth equivalent to $H_{D=0}$ below the still water level". Considering this definition, the corresponding active zone for the tests conducted in this study was approximately $28 \mathrm{D}_{\mathrm{n} 50^{2}}{ }^{2}$ when $H=H_{s}$ and $K_{D}=3.5$ (USACE [4]). The armor damage, $D$, provided by USACE [4] was related to the dimensionless armor damage, $S$, as noted in Table A.1. The active zone was slightly smaller when $H=H_{1 / 10}$ and $K_{D}=2.0$ (USACE [5]). The damage data presented in the USACE [4] was fitted by the empirical Eq. (A.1). Fig. A.1 shows a good agreement between Eq. (A.1) and damage data provided by Table A.1.

$\frac{H}{H_{D=0}}=\left(\frac{S}{1.4}\right)^{0.2}$

Table A.1. Dimensionless armor damage, $\mathrm{S}$, for $H=H_{s}$ as a function of $H / H_{D=0}$ and the percent of damage, $\mathrm{D}$.

\begin{tabular}{c|ccccccc}
\hline & \multicolumn{7}{|c}{ Relative wave height, $H / H_{D=0}$} \\
\cline { 2 - 8 }$H=H_{S}$ (USACE [4]) & 1.00 & 1.08 & 1.19 & 1.27 & 1.37 & 1.47 & 1.56 \\
\cline { 2 - 8 } & \multicolumn{7}{c}{ Percent Damage (D) } \\
\cline { 2 - 8 } & $0-5$ & $5-10$ & $10-15$ & $15-20$ & $20-30$ & $30-40$ & $40-50$ \\
\hline $\begin{array}{c}\text { Dimensionless Damage } \\
(S=0.28 D)\end{array}$ & 0.7 & 2.1 & 3.5 & 4.9 & 7.0 & 9.8 & 12.6 \\
\hline
\end{tabular}




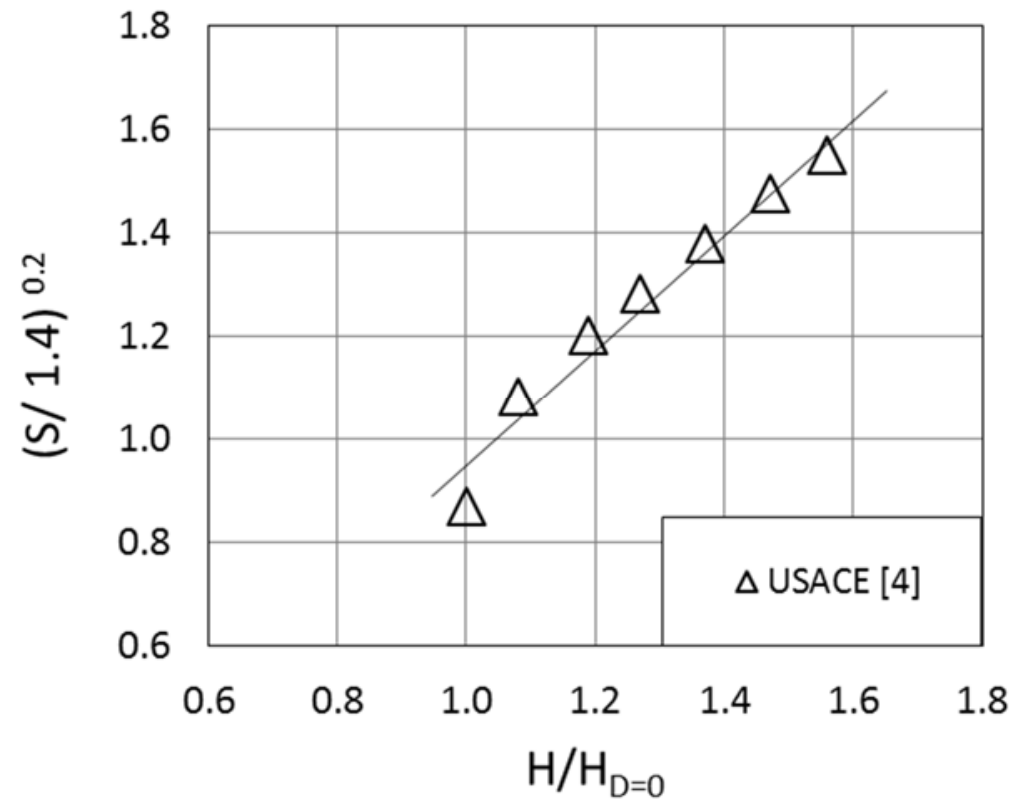

Fig. A.1. Linearized damage function fitted to data provided by USACE [4].

Eq. (A.2) combines Eqs. (1) and (A.1) to estimate the stability number as a function of the dimensionless armor damage parameter, $S$.

$\frac{H}{\Delta D_{n 50}}=\left(\frac{S}{1.4}\right)^{0.2}\left(K_{D} \cot \alpha\right)^{1 / 3}$

\section{Appendix B. References}

[1] Iribarren, R., 1938. Una fórmula para el cálculo de los diques de escollera. M. Bermejillo-Pasajes, Madrid, Spain.

[2] Iribarren, R., 1965. Formule pour le calcul des diques en enrochements naturels on elements artificieles. XXI Int. Navigation Congr., Sect. II-I, Stockholm, Sweden, 15-46.

[3] Hudson, R.Y., 1959. Laboratory investigation of rubble-mound breakwaters. Journal of the Waterways and Harbors Division, ASCE, 85(WW3), 93-121. 
[4] USACE, 1975. Shore Protection Manual, U.S. Army Coastal Engineering Research Center, U.S. Army Engineer Waterways Experiment Station, Vicksburg, Mississippi.

[5] USACE, 1984. Shore Protection Manual, U.S. Army Coastal Engineering Research Center, U.S. Army Engineer Waterways Experiment Station, Vicksburg, Mississippi.

[6] Van der Meer, J.W., 1988. Rock slopes and gravel beaches under wave attack. PhD Thesis. Thecnical University of Delft.

[7] Melby, J.A., Kobayashi, N., 1998. Progression and variability of damage on rubble mound breakwaters. J. Waterway, Port, Coastal, Ocean Eng., ASCE, 124(6), 286-294.

[8] Van Gent, M.R.A., Smale, A.J., Kuiper, C., 2003. Stability of rock slopes with shallow foreshores. Proc. Coastal Structures 2003, Portland, 100-112.

[9] Glukhovsky, B. H., 1966. Issledovanie morskogo vetrovogo volnenia (Study of sea wind waves). Leningrad, Gidrometeoizdat (in Russian).

[10] Hughes, S. A., Borgman, L. E., 1987. Beta-Rayleigh distribution for shallow-water wave heights. In: R. Dalrymple (ed), Proc. International Conference on Coastal Hydrodynamics, Delaware, USA, 17-31.

[11] Battjes, J.A., Groenendijk, H.W., 2000. Wave height distributions on shallow foreshores. Coastal Engineering, 40, 161-182.

[12] Mendez, F. J., Losada, I. J., Medina, R., 2004. Transformation model of wave height distribution on planar beaches. Coastal Engineering 50(3), 97-115.

[13] Mendez, F. J., Castanedo, S., 2007. A probability distribution for depth-limited extreme wave heights in a sea state. Coastal Engineering 54, 878-882. 
[14] Verhagen, H.J., Van Vledder, G., Eslami Arab, S., 2008. A practical method for design of coastal structures in shallow water. Proc. 31st International Conference on Coastal Engineering, ASCE, 2912-2922.

[15] Feuillet, J., Coeffe, Y., Bernier, J., Chaloin, B., 1987. Le dimensionnement des digues à talus. Éditions Eyrolles, Collection de la direction des études et recherches d'électricité de France, Vol.64 (in French).

[16] Jensen, T., Andersen, H., Grlilnbeck, J., Mansard, E. P. D., Davies, M. H., 1996. Breakwater stability under regular and irregular wave attack. Proc. 25th International Conference on Coastal Engineering, ASCE, 1679-1692.

[17] Broderick, L.L., 1983. Riprap Stability A Progress Report. Proc. Specialty Conference on Design, Construction, Maintenance and Performance of Coastal Structures, Arlington, VA, March 9-11, 1983. Coastal Structures '83, ASCE, 320-330.

[18] Van der Meer, J.W., 1988. Deterministic and probabilistic design of breakwater armor layers. J. Waterway, Port, Coastal, Ocean Eng., 114(1), 66-80.

[19] Medina, J.R., Hudspeth, R.T., Fassardi, C., 1994. Breakwater Armor Damage due to Wave Groups. J. Waterway, Port, Coastal, Ocean Eng., 120(2), 179-198.

[20] Thompson, D.M., Shuttler, R.M., 1975. Riprap design for wind wave attack. A laboratory study in random waves. Report EX 707, Hydraulic Research, Wallingford. [21] Lamberti, A., Tomassichio, G.R., Guiducci, F., 1994. Reshaping breakwaters in deep and shallow water conditions. Proc. 24th International Conference on Coastal Engineering, ASCE, 1343-1358. 
[22] Melby, J.A., 2001. Damage development on Stone armored breakwaters and revetments. ERDC/CHL CHETN-III-64, US Army Engineer Research and Development Center, Vicksburg, MS.

[23] Kobayashi, N., Cox, D. T., Wurjanto, A., 1990. Irregular wave reflection and runup on rough impermeable slopes. J. Waterway, Port, Coastal, Ocean Eng., 116(6), 708726.

[24] Kobayashi, N., Wurjanto, A., Cox, D. T., 1990. Rock slopes under irregular wave attack. Proc. 22nd International Conference on Coastal Engineering, ASCE, 13071319.

[25] Smith, G.M., Wallast, I., Van Gent, M.R.A., 2002. Rock slope stability with shallow foreshores. Proc., 28th International Conference on Coastal Engineering, ASCE, 1524 $-1536$.

[26] CIRIA, CUR, CETMEF, 2007. The Rock Manual. The Use of Rock in Hydraulic Engineering (2nd edition). C683, CIRIA, London.

[27] Hovestad, M., 2005. Breakwaters on steep foreshores: the influence of foreshore steepness on armour stability. M.Sc. thesis Delft. Delft University of Technology, Delft.

[28] Muttray M., Reedijk, B., 2008. Reanalysis of breakwater stability with steep foreshore. Proc. 25th International Conference on Coastal Engineering, ASCE, 33463357.

[29] Verhagen, H.J., J. Reedijk, J., Muttray, M., 2006. The effect of foreshore slope on breakwater stability. Proc. 30th International Conference on Coastal Engineering, ASCE, 4828-4840. 
[30] Herrera, M.P., Medina, J.R., 2015. Toe berm design for very shallow waters on steep sea bottoms. Coastal Engineering, 103, 67-77.

[31] Vidal, C., Medina, R., Lomónaco, P., 2006. Wave height parameter for damage description of rubble-mound breakwaters. Coastal Engineering, 53 (9), 711-722.

[32] Prevot, G., Boucher, O., Luck, M., Benoit, M., 2012. Stability of rubble mound breakwaters in shallow water and surf zone: an experimental study. Proc. 33rd International Conference on Coastal Engineering, ASCE, structures. 85.

[33] Medina, J.R., Molines, J., Gómez-Martín, M.E., 2014. Influence of armour porosity on the hydraulic stability of cube armour layers. Ocean Engineering, 88, 289-297.

[34] Gómez-Martín, M.E., Medina, J.R., 2006. Damage progression on cube armored breakwaters. Proc. 30th International Conference on Coastal Engineering, ASCE, $5229-5240$.

[35] Gómez-Martín, M.E., Medina, J.R., 2014. Heterogeneus Packing and Hydraulic Stability of Cube and Cubipod Armor Units. J. Waterway, Port, Coastal, Ocean Eng., ASCE, 140, 100-108.

[36] Figueres, M., Medina, J.R., 2004. Estimation of incident and reflected waves using a fully non-linear wave model. Proc. 29th International Conference on Coastal Engineering, ASCE, Singapore, 594-603.

[37] Losada, M.A., Desiré J.M., Alejo L.M., 1986. Stability of blocks as breakwater armor units. Journal of Structural Engineering, 112(11), 2392-2401.

[38] Vidal, C., Losada, M.A., Medina, R., 1991. Stability of mound breakwaters' head and trunk. J. Waterway, Port, Coastal, Ocean Eng., ASCE, 117(6), 570-587. 
[39] Gómez-Martín, M.E., 2015. Análisis de la evolución de averías en el manto principal de diques en talud formado por escolleras, cubos y Cubípodos [Unpublished PhD thesis]. Universitat Politècnica de València. doi:10.4995/Thesis/10251/59231.

[40] Van Gent, M.R.A., van den Boogaard, H.F.P., Pozueta, B., Medina, J.R., 2007. Neural network modelling of wave overtopping at coastal structures. Coastal Engineering, $54(8), 586-593$.

[41] Goda, Y., 1985. Random seas and design of maritime structures. University of Tokyo Press, Tokyo, Japan.

[42] Melby, J. A., 1999. Damage progression on rubble mound breakwaters. Technical Report CHL-99-17, U.S. Army Engineer Research and Development Center, Vicksburg, MS. Ph.D. diss., University of Delaware, Newark, DE.

[43] Van der Meer, J.W., 1985. Stability of rubble mound revetments and breakwaters uner random wave attack. ICE, Proc. Developments in Breakwaters, London, 141154. 